\title{
LA ESTRUCTURA DE EDADES Y EL OCIO DE LOS JOVENES: CIFRAS ESPAÑOLAS
}

Enrique Gil Calvo

Al hilo del Año Internacional de la Juventud, declarado para 1985 por la UNESCO, y como puntualización a determinadas polémicas despertadas por mi aplicación del modelo Easterlin al caso español ${ }^{1}$, se presentan aquí una serie de datos cuantitativos referentes a la reciente evolución de la población juvenil española, así como determinadas cuantificaciones objetivas de su empleo del tiempo libre ${ }^{2}$.

1 E. Gil Calvo, «La tendencia futura del paro y la fecundidad», en Revista Española de Investigaciones Sociológicas, núm. 27, julio-septiembre 1984, pp. 61-79; Los depredadores audiovisuales. Juventud urbana y cultura de masas, Madrid, Ed. Tecnos, 1985, pp. 33 a 65 .

2 E. Gil Calvo y E. Menéndez Vergara, Ocio y prácticas culturales de los jóvenes, Madrid, Instituto de la Juventud, Ministerio de Cultura, 1985, 282 pp. (publicación de la investigación monográfica que, con motivo del Año Internacional de la Juventud, la Subdirección General de Estudios y Documentación del Instituto de la Juventud encargó a Elena Menéndez Vergara). Debemos dar nuestras más reconocidas muestras de agradecimiento a José Luis Zárraga, coordinador del Informe Juventud en España y director del Programa de Investigaciones Básicas sobre la Juventud (Programa en el que se enmarcaba la monografía cuya investigación se confió a Elena Menéndez Vergara), y a Francisco Cánovas, subdirector de Estudios y Documentación del Instituto de la Juventud y «timonel» del Centro Riscal de Información y Documentación de Juventud, por sus generosas ayudas y confianzas, que sobrepasaron todo cuanto en buena lógica cabía espetar.

\section{RểS}




\section{Introducción}

En la figura 1 aparecen superpuestas mis estimaciones de las pirámides de edad correspondientes a la población española de 1965 y de 1985 . El objeto de superponerlas no es otro que el de poder advertir los cambios habidos, en ese lapso de veinte años, en la estructura de edades. Inmediatamente, de la sola contemplación de la figura 1 se advierte lo siguiente: la población infantil se ha reducido mucho, tanto en términos absolutos como relativos; la población adulta se ha reducido en términos relativos, puesto que apenas ha crecido en términos absolutos, y, en fin, tanto la población juvenil como la población anciana han visto incrementarse su número extraordinariamente, tanto en términos relativos como en absolutos.

Como es sabido, la estructura de las pirámides de edad no hace sino reflejar la historia reciente de su población. En efecto, en 1965 nos encontramos con exceso de adultos y escasez tanto de ancianos como de jóvenes. Jordi Nadal ha podido escribir: «la escasez relativa de jóvenes adultos, entre los 15 y los 29 años, es, en ese momento [entre 1960 y 1970], una de las características más salientes de la población española» ${ }^{3}$. Esa escasez relativa de jóvenes, que yo medí en anteriores trabajos ${ }^{4}$, no era sino el resultado del defecto de nacimientos producido durante la guerra civil y de la caída de la natalidad producida, como finalización del proceso de transición demográfica, durante las décadas de los treinta y los cuarenta.

Veinte años después, en 1985, las tornas ya se han cambiado por completo. Los jóvenes de 1965 han crecido y se han hecho adultos. Por tanto, a la escasez relativa de jóvenes de 1965 se corresponde la escasez relativa de adultos de 1985. Y al exceso relativo de adultos de 1965 se corresponde el exceso relativo de ancianos de 1985 . Además, puesto que entre 1955 y 1975 se produjo un baby boom cuyo máximo se centra en torno a 1965 (máxima escasez de jóvenes, luego máxima probabilidad para cada joven de emplearse, domiciliarse, casarse y reproducirse), en 1985 se produce un fortísimo exceso absoluto y relativo de jóvenes (con la consiguiente mínima probabilidad para cada joven de emplearse, domiciliarse, casarse y reproducirse) que, al verse obligados a reducir desde 1975 brutalmente su nupcialidad y su fecundidad, provocan la disminución absoluta y relativa de la población infantil en la pirámide de 1985.

${ }^{3}$ J. Nadal, La población española. Edición corregida y aumentada, Barcelona, Ed. Ariel, 1984, p. 260. Mi artículo del núm. 27 de la REIS, citado, finalizaba como sigue: «la sociología de la juventud debe centrar la investigación sobre su objeto de estudio privilegiado: la escasez relativa de jóvenes». Al escribir el artículo, yo desconocía todavía la última edición de Nadal, por lo que no había leído el texto citado, que confirma cuanto yo en mi artículo y mi libro postulaba.

4 E. Gil Calvo, «La tendencia futura del paro y la fecundidad», en Revista Española de Investigaciones Sociológicas, núm. 27, julio-septiembre 1984, pp. 61 a 79; Los depredadores audiovisuales. Juventud urbana y cultura de masas, Madrid, Ed. Tecnos, 1985, pp. 33 a 65 . 


\section{FIGURA 1}

La estructura edad/sexo del crecimiento poblacional babido desde 1965 basta 1985 mediante la superposición comparativa de sus respectivas pirámides

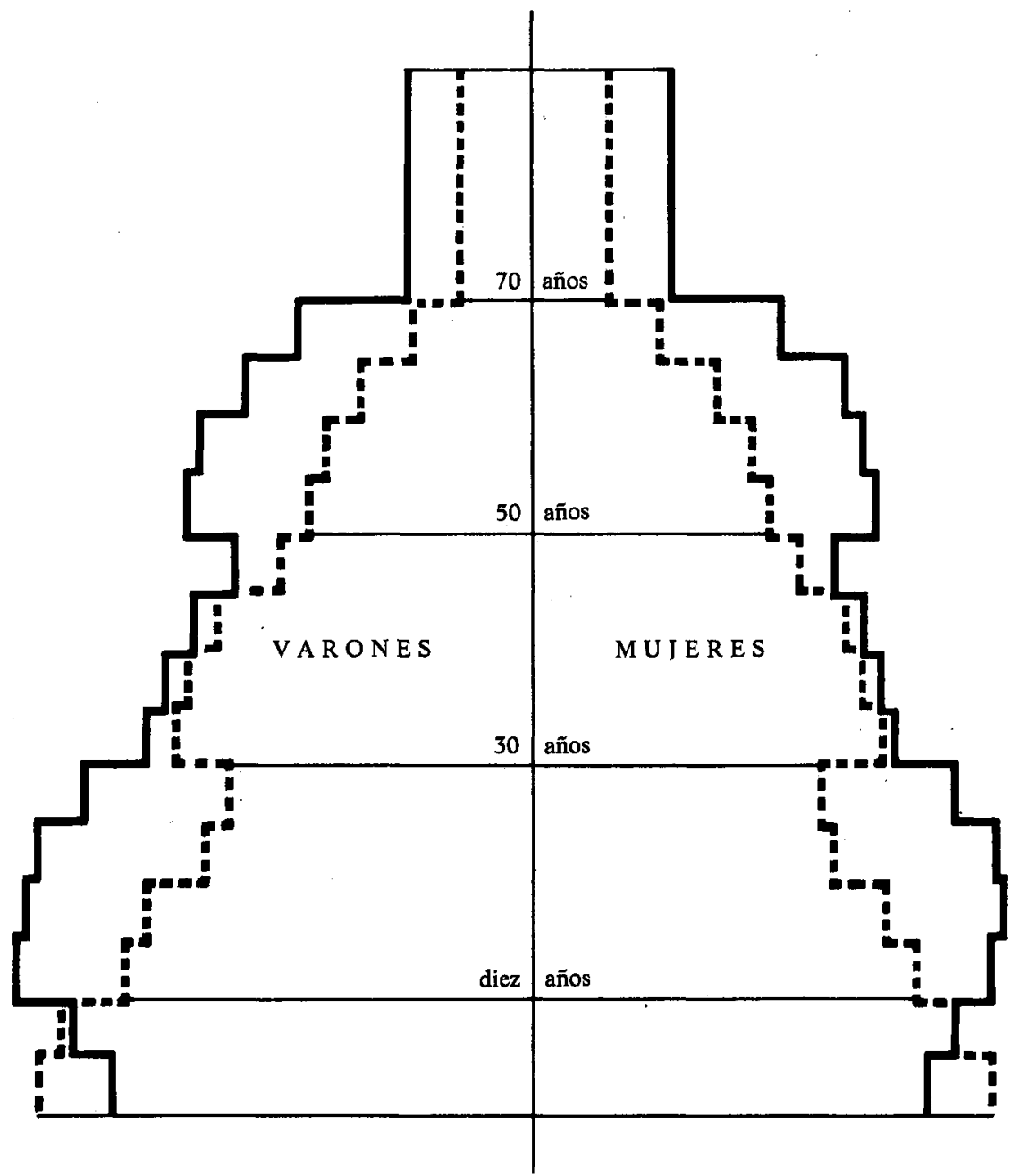

Pirámide poblacional estimada para 1985

Pirámide poblacional estimada para 1965

FuENTES: Censos del INE correspondientes a los años 1970 y 1981. 
En 1960, en unos Estados Unidos cuyo ciclo demográfico lleva diez años de adelanto sobre el europeo occidental en el que se inscribe la población española, escribía Norman Ryder: «En Estados Unidos, las cohortes que ahora llegan a la edad adulta tienen mayor tamaño que sus predecesoras. En consecuencia, crecieron en hogares más saturados de personas, asistieron a colegios desbordados de alumnos y amenazan ahora con inundar el mercado de trabajo. Quizá sus componentes tengan que posponer el matrimonio debido a la escasez de empleos o de viviendas, y tener un menor número de hijos. No constituye una coincidencia el que las cohortes de individuos que en Estados Unidos arrojan los niveles de fecundidad más altos de este siglo sean también aquellas que tienen un tamaño más reducido» ${ }^{5}$.

Quince y veinticinco años después, la coyuntura norteamericana entre 1972 y 1982, y la coyuntura europea entre 1981 y 1991, están dando la razón a Norman Ryder por entero. En efecto, las cohortes excesivamente numerosas, las nacidas durante los baby booms, son las más desgraciadas de todas, como advierten en su propia carne nuestros jóvenes actuales. En cambio, las cohortes escasas, las nacidas durante las depresiones económicas, sociales y demográficas, son las más felices o afortunadas de todas, como lo prueba el «destino manifiesto» de la actual generación dirigente española, nacida para triunfar, que protagonizó como juventud «rebelde» la tan traída y llevada "década prodigiosa» de los sesenta — show bizzness de mayo 68 incluido-, y que ahora, con madurez «responsable», gestiona la crisis económica monopolizando los puestos clave de la sociedad española. ¿Cabrá pronosticarles destino semejante a las futuras cohortes que tan escasamente nacen ahora?

Sea como fuere, la figura 1 evidencia con gráfica claridad que los actuales adultos son privilegiados debido a su escasez, mientras que, por el contrario, los actuales ancianos y jóvenes resultan negativamente discriminados debido precisamente a su misma excesiva abundancia. La expulsión de las personas mayores del mercado de trabajo, vía jubilaciones anticipadas; el recorte de las pensiones de invalidez y jubilación; las fortísimas resistencias sindicales a que los jóvenes ingresen en el mercado de trabajo, cuya entrada les aparece férreamente taponada, o, en fin, los altísimos índices de marginación juvenil (desempleo, delincuencia, drogadicción, anomía, etc.), no son sino el modo que ha elegido la sociedad española, gestionada por los actuales adultos que fueron los jóvenes de los sesenta, para convivir, que no enfrentarse, con la crisis demográfica que la figura 1 revela.

De los dos cuernos que tiene el problema -ancianos excedentarios y jóvenes excedentarios-, sólo abordaré aquí el relativo a la juventud. Sin duda,

${ }^{5}$ N. Ryder, «The Cohort as a Concept in the Study of Social Change», en American Sociological Review, vol. 23, 1960, pp. 843-861; citado en J. R. WEEKS, Sociología de la Población, Madrid, Alianza Universidad Textos, 1984, $471 \mathrm{pp}$. Excelente manual de demografía en el que aparecen multitud de aplicaciones del modelo Easterlin al análisis de la delincuencia juvenil, del fracaso escolar, del rendimiento intelectual, de la evolución de la fecundidad, de la estructura sexo/edad, etc. 
es el más vistoso de los dos, pero no es, desde luego, el más importante. Al fin y al cabo, el problema juvenil desaparecerá la próxima década, mientras que, por el contrario, el problema senil no hará más que agravarse. Por ello, si elijo centrarme en los jóvenes se debe no sólo a que sea éste su Año Internacional, sino, más que nada, a que su problema es mucho más leve.

\section{La cantidad de jóvenes}

En mis anteriores investigaciones pude estimar la evolución temporal de la cantidad relativa de jóvenes que se ha venido produciendo en España, así como la tendencia de su proyección futura ${ }^{6}$. De mis estimaciones se desprendía que el máximo en la cantidad relativa debía darse a fines de 1984, fecha a partir de la cual dicha cantidad relativa comenzaría a decrecer. Tales cálculos se basaban en la natalidad antecedente y, si estimaban cantidades relativas, era por derivarse de tasas de natalidad por mil habitantes.

Pues bien, aquí me propongo duplicar los cálculos, pero ahora atendiendo a la cantidad absoluta de jóvenes, y ya no a la relativa. Así, tal cantidad absoluta se basará, también, en la natalidad antecedente, pero ya no partiendo de tasas relativas de natalidad, como entonces, sino, ahora, a partir de los nacimientos totales, lo que permitirá estimar, para cada año, las variaciones que se vayan produciendo, imaginando tasas de mortalidad constantes, en la cantidad absoluta de jóvenes.

En la tabla 1 se registra el total de nacimientos, por sexo, habidos en España desde 1930 hasta la actualidad. A partir de tales cifras, en la tabla 2 se estima el número absoluto de jóvenes con edades comprendidas entre 15 y 24 años, y el número absoluto de jóvenes con edades comprendidas entre 15 y 29 años, por sexo, que hubiera habido en España desde 1954 y 1959 , respectivamente, en ausencia de mortalidad. Por supuesto, el número real de jóvenes habrá sido menor, dadas tasas determinadas de emigración y mortalidad. Pero como lo que aquí más interesa es proyectar las variaciones de la tendencia futura, los cálculos obtenidos a partir tan sólo de los nacimientos antecedentes bastan, ya que cabe suponer que el efecto distorsionador inducido por la emigración y la mortalidad no afectará las variaciones que sufra la tendencia. Además, así se mantiene la misma metodología seguida para estimar la tendencia de las cifras relativas.

Pues bien, en la figura 2 aparece gráficamente reflejada la tendencia seguida por la cantidad absoluta de jóvenes, así como su proyección futura, y ello tanto para un concepto restringido de juventud ( 15 a 24 años) como para un concepto ampliado ( 15 a 29 años). Además, y como punto de referencia relativo al fondo de la discusión, en la figura 2 se registra igualmente el

-E. Gil Calvo, «La tendencia futura del paro...», artículo citado, y Los depredadores audiovisuales, libro citado. 


\section{TABLA 1}

Evolución del número absoluto de nacimientos producidos en España, desde 1930 basta 1982, en miles, por sexo, y tasa de desempleo en porcentaje de parados sobre total de población activa, desde 1964 basta 1984

\begin{tabular}{|c|c|c|c|c|c|c|c|c|}
\hline$A \tilde{n} o s$ & $\begin{array}{l}\text { Ambos } \\
\text { sexos }\end{array}$ & Varón & Mujer & $A \bar{n} o s$ & $\begin{array}{l}\text { Ambos } \\
\text { sexos }\end{array}$ & Varón & Mujer & $\begin{array}{c}\text { Tasa de } \\
\text { desempleo }\end{array}$ \\
\hline $\begin{array}{l}1930 \\
1931 \\
1932 \\
1933 \\
1934\end{array}$ & $\begin{array}{l}660 \\
649 \\
670 \\
668 \\
638\end{array}$ & $\begin{array}{l}342 \\
335 \\
346 \\
344 \\
328\end{array}$ & $\begin{array}{l}318 \\
314 \\
324 \\
324 \\
310\end{array}$ & $\begin{array}{l}1960 \\
1961 \\
1962 \\
1963 \\
1964\end{array}$ & $\begin{array}{l}655 \\
646 \\
650 \\
662 \\
689\end{array}$ & $\begin{array}{l}337 \\
332 \\
334 \\
340 \\
353\end{array}$ & $\begin{array}{l}318 \\
314 \\
316 \\
322 \\
336\end{array}$ & 1,81 \\
\hline $\begin{array}{l}1935 \\
1936 \\
1937 \\
1938 \\
1939\end{array}$ & $\begin{array}{l}632 \\
614 \\
566 \\
506 \\
420\end{array}$ & $\begin{array}{l}325 \\
315 \\
291 \\
261 \\
217\end{array}$ & $\begin{array}{l}307 \\
299 \\
275 \\
245 \\
203\end{array}$ & $\begin{array}{l}1965 \\
1966 \\
1967 \\
1968 \\
1969\end{array}$ & $\begin{array}{l}668 \\
662 \\
672 \\
659 \\
658\end{array}$ & $\begin{array}{l}342 \\
340 \\
345 \\
338 \\
338\end{array}$ & $\begin{array}{l}326 \\
322 \\
327 \\
321 \\
320\end{array}$ & $\begin{array}{l}1,24 \\
0,92 \\
1,10 \\
1,09 \\
0,92\end{array}$ \\
\hline $\begin{array}{l}1940 \\
1941 \\
1942 \\
1943 \\
1944\end{array}$ & $\begin{array}{l}628 \\
508 \\
528 \\
604 \\
599\end{array}$ & $\begin{array}{l}324 \\
262 \\
273 \\
311 \\
308\end{array}$ & $\begin{array}{l}304 \\
246 \\
255 \\
293 \\
291\end{array}$ & $\begin{array}{l}1970 \\
1971 \\
1972 \\
1973 \\
1974\end{array}$ & $\begin{array}{l}656 \\
665 \\
665 \\
666 \\
682\end{array}$ & $\begin{array}{l}337 \\
342 \\
342 \\
342 \\
350\end{array}$ & $\begin{array}{l}319 \\
323 \\
323 \\
324 \\
332\end{array}$ & $\begin{array}{l}1,15 \\
1,52 \\
2,13 \\
2,41 \\
2,94\end{array}$ \\
\hline $\begin{array}{l}1945 \\
1946 \\
1947 \\
1948 \\
1949\end{array}$ & $\begin{array}{l}618 \\
578 \\
582 \\
635 \\
595\end{array}$ & $\begin{array}{l}317 \\
296 \\
299 \\
326 \\
305\end{array}$ & $\begin{array}{l}301 \\
282 \\
283 \\
309 \\
290\end{array}$ & $\begin{array}{l}1975 \\
1976 \\
1977 \\
1978 \\
1979\end{array}$ & $\begin{array}{l}669 \\
677 \\
656 \\
637 \\
593\end{array}$ & $\begin{array}{l}346 \\
349 \\
339 \\
330 \\
306\end{array}$ & $\begin{array}{l}323 \\
328 \\
317 \\
307 \\
287\end{array}$ & $\begin{array}{r}4,67 \\
5,27 \\
6,28 \\
8,23 \\
10,14\end{array}$ \\
\hline $\begin{array}{l}1950 \\
1951 \\
1952 \\
1953 \\
1954\end{array}$ & $\begin{array}{l}559 \\
561 \\
586 \\
583 \\
571\end{array}$ & $\begin{array}{l}287 \\
288 \\
302 \\
299 \\
292\end{array}$ & $\begin{array}{l}272 \\
273 \\
284 \\
284 \\
279\end{array}$ & $\begin{array}{l}1980 \\
1981 \\
1982 \\
1983 \\
1984\end{array}$ & $\begin{array}{l}565 \\
532 \\
510\end{array}$ & $\begin{array}{l}293 \\
275 \\
264\end{array}$ & $\begin{array}{l}272 \\
257 \\
246\end{array}$ & $\begin{array}{l}12,60 \\
15,39 \\
17,06 \\
18,42 \\
21,69\end{array}$ \\
\hline $\begin{array}{l}1955 \\
1956 \\
1957 \\
1958 \\
1959\end{array}$ & $\begin{array}{l}592 \\
601 \\
640 \\
646 \\
647\end{array}$ & $\begin{array}{l}304 \\
308 \\
328 \\
331 \\
332\end{array}$ & $\begin{array}{l}288 \\
293 \\
312 \\
315 \\
315\end{array}$ & & & & & \\
\hline
\end{tabular}

Fuentes: Para las cifras de nacimientos, Anuario Estadístico 1983, del Instituto Nacional de Estadística, Madrid, 1984; para las cifras de desempleo, Encuesta de Población Activa, del Instituto Nacional de Estadística, en sus ejemplares correspondientes al $4 .^{\circ}$ trimestre de cada año. 


\section{TABLA 2}

Evolución del número absoluto de jóvenes entre 1954 y 1997, estimado a partir de los nacimientos producidos anteriormente $y$ en ausencia de mortalidad $y$ emigración. Miles de jóvenes de 15 a 24 y de 15 a 29 años

\begin{tabular}{|c|c|c|c|c|c|c|c|c|c|c|}
\hline \multirow[b]{2}{*}{ Años } & \multicolumn{4}{|c|}{ NACIDOS ENTRE 15 Y 24 AÑOS } & \multirow{2}{*}{$\frac{\text { ANTES }}{\text { Mujer }}$} & \multicolumn{5}{|c|}{ NACIDOS ENTRE 15 Y 29 AÑOS ANTES } \\
\hline & Nacidos & entre & Total & Varón & & Nacidos & entre & Total & Varón & Mujer \\
\hline 1954 & $1930 y$ & 1939 & 6.023 & 3.104 & 2.919 & & & & & \\
\hline $\begin{array}{l}1955 \\
1956 \\
1957 \\
1958 \\
1959\end{array}$ & $\begin{array}{l}1931 \mathrm{y} \\
1932 \mathrm{y} \\
1933 \mathrm{y} \\
1934 \mathrm{y} \\
1935 \mathrm{y}\end{array}$ & $\begin{array}{l}1940 \\
1941 \\
1942 \\
1943 \\
1944\end{array}$ & $\begin{array}{l}5.991 \\
5.850 \\
5.708 \\
5.644 \\
5.605\end{array}$ & $\begin{array}{l}3.086 \\
3.013 \\
2.940 \\
2.907 \\
2.887\end{array}$ & $\begin{array}{l}2.905 \\
2.837 \\
2.768 \\
2.737 \\
2.718\end{array}$ & $1930 \mathrm{y}$ & 1944 & 8.890 & 4.582 & 4.308 \\
\hline $\begin{array}{l}1960 \\
1961 \\
1962 \\
1963 \\
1964\end{array}$ & $\begin{array}{l}1936 \mathrm{y} \\
1937 \mathrm{y} \\
1938 \mathrm{y} \\
1939 \mathrm{y} \\
1940 \mathrm{y}\end{array}$ & $\begin{array}{l}1945 \\
1946 \\
1947 \\
1948 \\
1949\end{array}$ & $\begin{array}{l}5.591 \\
5.555 \\
5.571 \\
5.700 \\
5.875\end{array}$ & $\begin{array}{l}2.879 \\
2.860 \\
2.868 \\
2.933 \\
3.021\end{array}$ & $\begin{array}{l}2.712 \\
2.695 \\
2.703 \\
2.767 \\
2.854\end{array}$ & $\begin{array}{l}1931 \mathrm{y} \\
1932 \mathrm{y} \\
1933 \mathrm{y} \\
1934 \mathrm{y} \\
1935 \mathrm{y}\end{array}$ & $\begin{array}{l}1945 \\
1946 \\
1947 \\
1948 \\
1949\end{array}$ & $\begin{array}{l}8.848 \\
8.777 \\
8.689 \\
8.656 \\
8.613\end{array}$ & $\begin{array}{l}4.557 \\
4.518 \\
4.471 \\
4.453 \\
4.430\end{array}$ & $\begin{array}{l}4.291 \\
4.259 \\
4.218 \\
4.203 \\
4.183\end{array}$ \\
\hline $\begin{array}{l}1965 \\
1966 \\
1967 \\
1968 \\
1969\end{array}$ & $\begin{array}{l}1941 \mathrm{y} \\
1942 \mathrm{y} \\
1943 \mathrm{y} \\
1944 \mathrm{y} \\
1945 \mathrm{y}\end{array}$ & $\begin{array}{l}1950 \\
1951 \\
1952 \\
1953 \\
1954\end{array}$ & $\begin{array}{l}5.806 \\
5.859 \\
5.917 \\
5.896 \\
5.868\end{array}$ & $\begin{array}{l}2.984 \\
3.010 \\
3.039 \\
3.027 \\
3.011\end{array}$ & $\begin{array}{l}2.822 \\
2.849 \\
2.878 \\
2.869 \\
2.857\end{array}$ & $\begin{array}{l}1936 \mathrm{y} \\
1937 \mathrm{y} \\
1938 \mathrm{y} \\
1939 \mathrm{y} \\
1940 \mathrm{y}\end{array}$ & $\begin{array}{l}1950 \\
1951 \\
1952 \\
1953 \\
1954\end{array}$ & $\begin{array}{l}8.540 \\
8.487 \\
8.507 \\
8.584 \\
8.735\end{array}$ & $\begin{array}{l}4.392 \\
4.365 \\
4.376 \\
4.414 \\
4.489\end{array}$ & $\begin{array}{l}4.148 \\
4.122 \\
4.131 \\
4.170 \\
4.246\end{array}$ \\
\hline $\begin{array}{l}1970 \\
1971 \\
1972 \\
1973 \\
1974\end{array}$ & $\begin{array}{l}1946 \mathrm{y} \\
1947 \mathrm{y} \\
1948 \mathrm{y} \\
1949 \mathrm{y} \\
1950 \mathrm{y}\end{array}$ & $\begin{array}{l}1955 \\
1956 \\
1957 \\
1958 \\
1959\end{array}$ & $\begin{array}{l}5.842 \\
5.865 \\
5.923 \\
5.934 \\
5.986\end{array}$ & $\begin{array}{l}2.998 \\
3.010 \\
3.039 \\
3.044 \\
3.071\end{array}$ & $\begin{array}{l}2.844 \\
2.855 \\
2.884 \\
2.890 \\
2.915\end{array}$ & $\begin{array}{l}1941 \mathrm{y} \\
1942 \mathrm{y} \\
1943 \mathrm{y} \\
1944 \mathrm{y} \\
1945 \mathrm{y}\end{array}$ & $\begin{array}{l}1955 \\
1956 \\
1957 \\
1958 \\
1959\end{array}$ & $\begin{array}{l}8.699 \\
8.792 \\
8.904 \\
8.946 \\
8.994\end{array}$ & & $\begin{array}{l}4.230 \\
4.277 \\
4.334 \\
4.356 \\
4.380\end{array}$ \\
\hline $\begin{array}{l}1975 \\
1976 \\
1977 \\
1978 \\
1979\end{array}$ & $\begin{array}{l}1951 \mathrm{y} \\
1952 \mathrm{y} \\
1953 \mathrm{y} \\
1954 \mathrm{y} \\
1955 \mathrm{y}\end{array}$ & $\begin{array}{l}1960 \\
1961 \\
1962 \\
1963 \\
1964\end{array}$ & $\begin{array}{l}6.082 \\
6.167 \\
6.231 \\
6.310 \\
6.428\end{array}$ & $\begin{array}{l}3.121 \\
3.165 \\
3.197 \\
3.238 \\
3.299\end{array}$ & $\begin{array}{l}2.961 \\
3.002 \\
3.034 \\
3.072 \\
3.129\end{array}$ & $\begin{array}{l}1946 \mathrm{y} \\
1947 \mathrm{y} \\
1948 \mathrm{y} \\
1949 \mathrm{y} \\
1950 \mathrm{y}\end{array}$ & $\begin{array}{l}1960 \\
1961 \\
1962 \\
1963 \\
1964\end{array}$ & $\begin{array}{l}9.031 \\
9.099 \\
9.167 \\
9.194 \\
9.288\end{array}$ & & $\begin{array}{l}4.397 \\
4.429 \\
4.462 \\
4.475 \\
4.521\end{array}$ \\
\hline $\begin{array}{l}1980 \\
1981 \\
1982 \\
1983 \\
1984\end{array}$ & $\begin{array}{l}1956 \mathrm{y} \\
1957 \mathrm{y} \\
1958 \mathrm{y} \\
1959 \mathrm{y} \\
1960 \mathrm{y}\end{array}$ & $\begin{array}{l}1965 \\
1966 \\
1967 \\
1968 \\
1969\end{array}$ & $\begin{array}{l}6.504 \\
6.565 \\
6.597 \\
6.610 \\
6.621\end{array}$ & $\begin{array}{l}3.337 \\
3.369 \\
3.386 \\
3.393 \\
3.399\end{array}$ & $\begin{array}{l}3.167 \\
3.196 \\
3.211 \\
3.217 \\
3.222\end{array}$ & $\begin{array}{l}1951 \mathrm{y} \\
1952 \mathrm{y} \\
1953 \mathrm{y} \\
1954 \mathrm{y} \\
1955 \mathrm{y}\end{array}$ & $\begin{array}{l}1965 \\
1966 \\
1967 \\
1968 \\
1969\end{array}$ & $\begin{array}{l}9.397 \\
9.498 \\
9.584 \\
9.660 \\
9.747\end{array}$ & $\begin{array}{l}4.822 \\
4.874 \\
4.917 \\
4.956 \\
5.002\end{array}$ & $\begin{array}{l}4.575 \\
4.624 \\
4.667 \\
4.704 \\
4.745\end{array}$ \\
\hline $\begin{array}{l}1985 \\
1986 \\
1987 \\
1988 \\
1989\end{array}$ & $\begin{array}{l}1961 \mathrm{y} \\
1962 \mathrm{y} \\
1963 \mathrm{y} \\
1964 \mathrm{y} \\
1965 \mathrm{y}\end{array}$ & $\begin{array}{l}1970 \\
1971 \\
1972 \\
1973 \\
1974\end{array}$ & $\begin{array}{l}6.622 \\
6.641 \\
6.656 \\
6.660 \\
6.653\end{array}$ & $\begin{array}{l}3.399 \\
3.409 \\
3.417 \\
3.419 \\
3.416\end{array}$ & $\begin{array}{l}3.223 \\
3.232 \\
3.239 \\
3.241 \\
3.237\end{array}$ & $\begin{array}{l}1956 \mathrm{y} \\
1957 \mathrm{y} \\
1958 \mathrm{y} \\
1959 \mathrm{y} \\
1960 \mathrm{y}\end{array}$ & $\begin{array}{l}1970 \\
1971 \\
1972 \\
1973 \\
1974\end{array}$ & $\begin{array}{l}9.811 \\
9.875 \\
9.900 \\
9.920 \\
9.955\end{array}$ & $\begin{array}{l}5.035 \\
5.069 \\
5.083 \\
5.094 \\
5.112\end{array}$ & $\begin{array}{l}4.776 \\
4.806 \\
4.817 \\
4.826 \\
4.843\end{array}$ \\
\hline $\begin{array}{l}1990 \\
1991 \\
1992 \\
1993 \\
1994\end{array}$ & $\begin{array}{l}1966 \mathrm{y} \\
1967 \mathrm{y} \\
1968 \mathrm{y} \\
1969 \mathrm{y} \\
1970 \mathrm{y}\end{array}$ & $\begin{array}{l}1975 \\
1976 \\
1977 \\
1978 \\
1979\end{array}$ & $\begin{array}{l}6.654 \\
6.669 \\
6.653 \\
6.631 \\
6.566\end{array}$ & $\begin{array}{l}3.420 \\
3.429 \\
3.423 \\
3.415 \\
3.383\end{array}$ & $\begin{array}{l}3.234 \\
3.240 \\
3.230 \\
3.216 \\
3.183\end{array}$ & $\begin{array}{l}1961 \mathrm{y} \\
1962 \mathrm{y} \\
1963 \mathrm{y} \\
1964 \mathrm{y} \\
1965 \mathrm{y}\end{array}$ & $\begin{array}{l}1975 \\
1976 \\
1977 \\
1978 \\
1979\end{array}$ & $\begin{array}{r}9.969 \\
10.000 \\
10.006 \\
9.981 \\
9.885\end{array}$ & $\begin{array}{l}5.121 \\
5.138 \\
5.143 \\
5.133 \\
5.086\end{array}$ & $\begin{array}{l}4.848 \\
4.862 \\
4.863 \\
4.848 \\
4.799\end{array}$ \\
\hline $\begin{array}{l}1995 \\
1996 \\
1997\end{array}$ & $\begin{array}{l}1971 \mathrm{y} \\
1972 \mathrm{y} \\
1973 \mathrm{y}\end{array}$ & $\begin{array}{l}1980 \\
1981 \\
1982\end{array}$ & $\begin{array}{l}6.475 \\
6.342 \\
6.187\end{array}$ & $\begin{array}{l}3.339 \\
3.272 \\
3.194\end{array}$ & $\begin{array}{l}3.136 \\
3.070 \\
2.993\end{array}$ & $\begin{array}{l}1966 \mathrm{y} \\
1967 \mathrm{y} \\
1968 \mathrm{y}\end{array}$ & $\begin{array}{l}1980 \\
1981 \\
1982\end{array}$ & $\begin{array}{l}9.782 \\
9.652 \\
9.490\end{array}$ & $\begin{array}{l}5.037 \\
4.972 \\
4.891\end{array}$ & $\begin{array}{l}4.745 \\
4.680 \\
4.599\end{array}$ \\
\hline
\end{tabular}

FUENTE: Tabla 1. 


\section{FIGURA 2}

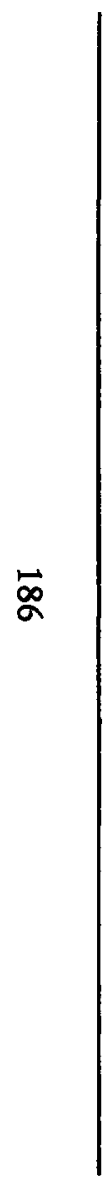

Evolución del número absoluto de jóvenes

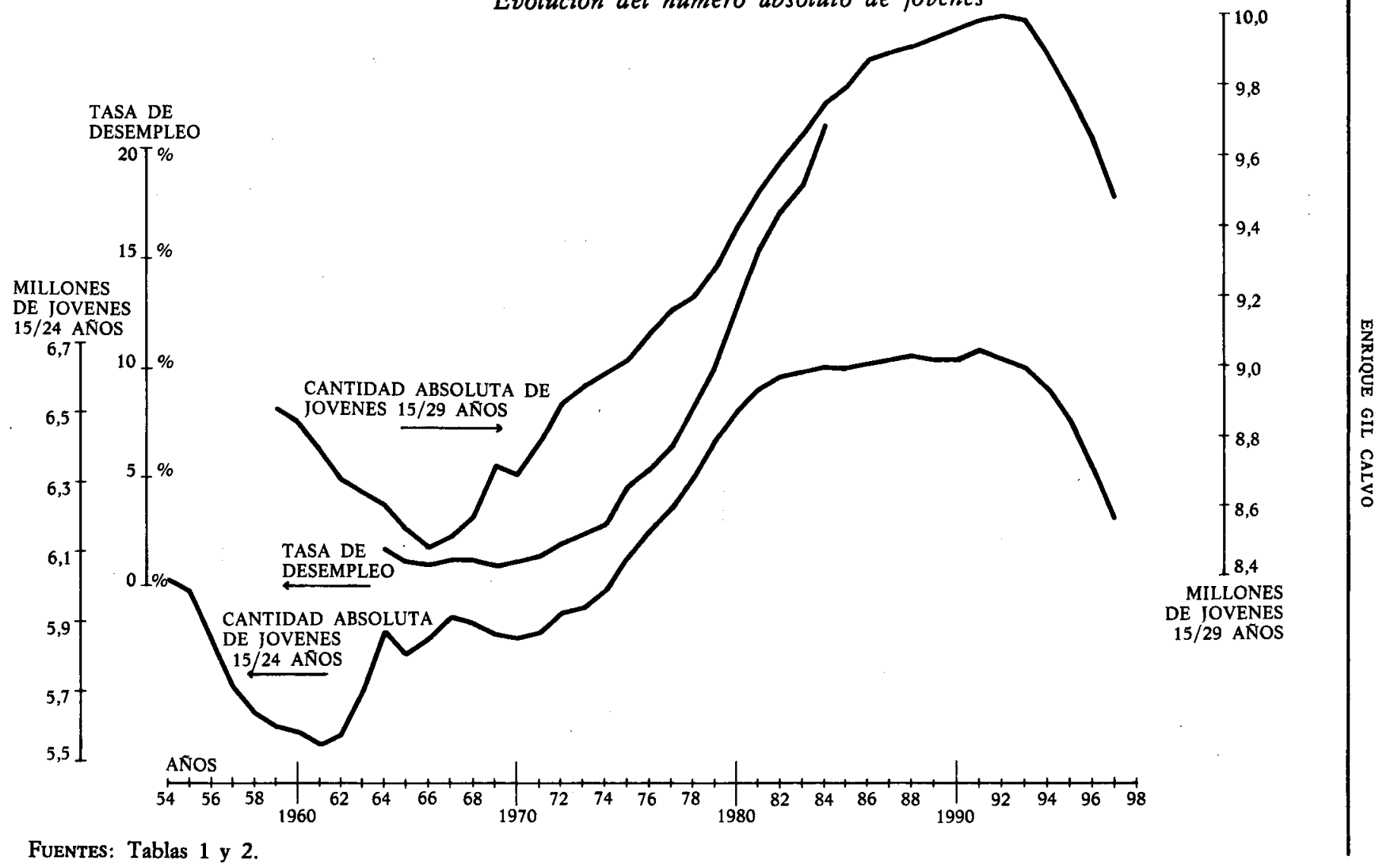


índice de desempleo (porcentaje de parados sobre total de población activa), cuyas cifras se adjuntan en la tabla 1.

$\mathrm{Si}$ comparamos estos datos de cantidad absoluta de jóvenes con los que publiqué anteriormente de cantidad relativa ${ }^{7}$, podrá advertirse lo siguiente: el mínimo en el número de jóvenes, tanto en cifras absolutas como relativas, se dio en 1966 ó 1967. En cambio, el máximo en el número de jóvenes se dará en diferente fecha, según consideremos cifras absolutas o relativas; en efecto, como publiqué, el máximo en el número de jóvenes, en cifras relativas, debió darse a fines de 1984; en cambio, el máximo en el número de jóvenes, en cifras absolutas, habrá de darse en 1991 ó 1992, como se desprende de los datos de la tabla 2, gráficamente representados en la figura 2 .

El fondo de la discusión es el siguiente: ¿está relacionado el nivel de empleo con el tamaño de las cohortes de jóvenes? Parece darse una cierta relación, por indirecta que sea, como prueban todas las cifras de los países industrializados: la escasez de jóvenes favorece el pleno empleo (década de los sesenta), mientras que el exceso de jóvenes parece generar altas tasas de desempleo (década actual). Si esto es así, parece conveniente averiguar cuándo cambiará la tendencia, es decir, cuándo se producirá el máximo exceso de jóvenes, momento a partir del cual el número de jóvenes comenzará a reducirse y, por lo tanto, el nivel de empleo comenzará a mejorar. El problema reside en que ese momento, el del máximo en el número de jóvenes, no puede identificarse con exactitud, ya que varía desde 1984 , si atendemos a las cifras relativas, hasta 1991 , si atendemos a las absolutas. ¿Cabe deducir que el paro creció hasta 1984, que se mantendrá estable desde 1985 hasta 1991 y que sólo podrá descender a partir de 1992?

\section{La estructura edad/sexo del mercado español de trabajo}

Olvidémonos ahora del problema de la medida en que el tamaño de las cohortes juveniles influye en la determinación del nivel de empleo, y olvidémonos, por tanto, de cuál será la futura tendencia del tamaño de las cohortes juveniles; sea como fuere, el caso es que se ha producido un crecimiento diferencial de las diferentes cohortes coexistentes en función de su edad, y que esa diferencialidad afecta no sólo a la magnitud poblacional de cada cohorte, sino, además, también afecta a la posición que cada cohorte ocupa en el mercado de trabajo. Dicho de otro modo: en la figura 1 pude evidenciar que, en los últimos veinte años, se ha dado un fortísimo crecimiento en el número de jóvenes y de viejos, pero que no ha sido así, sino todo lo contrario, por lo que respecta al número de adultos; pues bien, siendo esto así, ¿qué consecuencias ha desencadenado este fenómeno sobre la estructura de edades del mercado español de trabajo?

7 E. Gil Calvo, «La tendencia futura del paro...», artículo citado, y Los depredadores audiovisuales, libro y páginas citados. 
En el cuadro 1 aparecen las cifras de población activa correspondientes al año 1974 (momento en el que va a tener lugar la crisis económica internacional, pero cuyo estallido todavía no ha podido generar influencias sobre la población activa) y a la actualidad; podrá verse, pues, cuál ha sido el efecto producido por estos diez años de crisis de empleo. Ante todo, cabe advertir lo siguiente: si sólo hubieran actuado fuerzas económicas (encarecimiento energético y del trabajo, inflación, ausencia de inversión, caída del comercio internacional, etc.), las modificaciones inducidas sobre la población activa deberían haberse distribuido por su estructura de sexo y edad homogéneamente o al azar. Ahora bien, lejos de ser así, advertiremos inmediatamente, tras la contemplación de los diferenciales habidos entre 1984 y 1974 (registrados en las columnas situadas a la derecha del cuadro 1), que los cambios producidos, lejos de repartirse por igual o al azar entre las diferentes cohortes, lo han hecho muy discriminadamente, según cuál fuere el sexo y la edad. Es decir, los efectos «perversos» de las fuerzas económicas han repercutido diferencialmente en función del sexo y la edad, lo que, para cualquier observador dotado de sentido común, revela la presencia actuante de fuerzas no económicas, fuerzas sociales o demográficas, que han producido la consecuencia de que los sujetos se hayan visto más o menos afectados por aquellas fuerzas económicas según cuál fuere su sexo y su edad.

En realidad, se trata de algo brutal, dada su enormidad. Vimos, por la figura 1, que los adultos reducían su número y que los jóvenes y los viejos lo aumentaban. Pues bien, a pesar de eso, los adultos incrementan su participación en la población activa a costa de las reducciones experimentadas por los jóvenes y los viejos. Este fenómeno, demográficamente contracíclico, afecta tanto a los hombres como a las mujeres, aunque se intensifica muchísimo entre estas últimas, y es registrable tanto en las cifras absolutas (miles de activos) como en las relativas (tasas y cuotas de actividad de cada grupo de sexo y edad): los adultos y las adultas, en función de su escasez, han logrado el poder de expulsar a los jóvenes y a los viejos de ambos sexos de la población activa.

Pero, naturalmente, el de «población activa» es un concepto de suma equivocidad, sobre todo si, como es el caso que nos ocupa, sus datos se obtienen por encuesta. Dado que son activos quienes confiesan trabajar o estar dispuestos a trabajar, podría darse el caso de que la diferencialidad que acabamos de ver no se refiriese tanto a la actividad económica objetiva como a la subjetiva; es decir, que esos cambios en función del sexo y la edad no se refiriesen tanto a la participación «real» en el mercado de trabajo como a la «percepción» que cada grupo de edad y sexo tuviese respecto a su participación real: o sea, que, como por arte de magia demográfica, de pronto los viejos y los jóvenes se hubiesen convertido en escépticos pesimistas frente a unos ingenuos adultos súbitamente trastocados en optimistas. Para despejar 


\section{CUADRO 1}

La evolución de la población activa española, de 1974 a 1984

\begin{tabular}{|c|c|c|c|c|c|c|c|c|c|}
\hline & \multicolumn{3}{|c|}{ AÑo 1974} & \multicolumn{3}{|c|}{ AÑo 1984} & \multicolumn{3}{|c|}{ Diferenciales $74-84$} \\
\hline & $\begin{array}{l}\text { Activos } \\
\text { (miles) }\end{array}$ & $\begin{array}{c}\text { Tasas } \\
(\%)\end{array}$ & $\begin{array}{c}\text { Cuotas } \\
(\%)\end{array}$ & $\begin{array}{l}\text { Activos } \\
\text { (miles) }\end{array}$ & $\begin{array}{c}\text { Tasas } \\
(\%)\end{array}$ & $\begin{array}{c}\text { Cuotas } \\
(\%)\end{array}$ & $\begin{array}{l}\text { Activos } \\
\text { (miles) }\end{array}$ & $\begin{array}{c}\text { Tasas } \\
(\%)\end{array}$ & $\begin{array}{c}\text { Cuotas } \\
(\%)\end{array}$ \\
\hline \multicolumn{10}{|l|}{ Ambos sexos } \\
\hline $\begin{array}{lllllllll}\text { TOTAL } & \ldots & \ldots & \ldots & \ldots & \ldots & \ldots & \ldots & \ldots\end{array}$ & 13.208 & 58 & 100 & 13.161 & 54 & 100 & -47 & -4 & 0 \\
\hline $\begin{array}{lllllllllll}15-24 \text { años } & \ldots & \ldots & \ldots & \ldots & \ldots & \ldots & \ldots & \ldots & \ldots \\
25-39 \text { años } & \ldots & \ldots & \ldots & \ldots & \ldots & \ldots & \ldots & \ldots & \ldots \\
40-54 \text { años } & \ldots & \ldots & \ldots & \ldots & \ldots & \ldots & \ldots & \ldots & \ldots \\
55-69 & \text { años } & \ldots & \ldots & \ldots & \ldots & \ldots & \ldots & \ldots & \ldots & \ldots\end{array}$ & $\begin{array}{l}3.242 \\
3.631 \\
4.259 \\
2.076\end{array}$ & $\begin{array}{l}61 \\
63 \\
62 \\
42\end{array}$ & $\begin{array}{l}25 \\
27 \\
32 \\
16\end{array}$ & $\begin{array}{l}2.912 \\
4.517 \\
3.776 \\
1.956\end{array}$ & $\begin{array}{l}52 \\
69 \\
59 \\
34\end{array}$ & $\begin{array}{l}22 \\
34 \\
29 \\
15\end{array}$ & $\begin{array}{r}-330 \\
+886 \\
-483 \\
-120\end{array}$ & $\begin{array}{r}-9 \\
+6 \\
-3 \\
-8\end{array}$ & $\begin{array}{l}-3 \\
+7 \\
-3 \\
-1\end{array}$ \\
\hline \multicolumn{10}{|l|}{ Varones } \\
\hline $\begin{array}{lllllllll}\text { TOTAL } & \ldots & \ldots & \ldots & \ldots & \ldots & \ldots & \ldots & \ldots\end{array}$ & 9.406 & 84 & 71 & 9.204 & 76 & 70 & -202 & -8 & -1 \\
\hline $\begin{array}{lllllllllll}15-24 & \text { años } & \ldots & \ldots & \ldots & \ldots & \ldots & \ldots & \ldots & \ldots & \ldots \\
25-39 & \text { años } & \ldots & \ldots & \ldots & \ldots & \ldots & \ldots & \ldots & \ldots & \ldots \\
40-54 \text { años } & \ldots & \ldots & \ldots & \ldots & \ldots & \ldots & \ldots & \ldots & \ldots \\
55-69 & \text { años } & \ldots & \ldots & \ldots & \ldots & \ldots & \ldots & \ldots & \ldots & \ldots\end{array}$ & $\begin{array}{l}1.899 \\
2.740 \\
3.249 \\
1.518\end{array}$ & $\begin{array}{l}70 \\
97 \\
96 \\
68\end{array}$ & $\begin{array}{l}14 \\
21 \\
25 \\
11\end{array}$ & $\begin{array}{l}1.679 \\
3.153 \\
2.888 \\
1.484\end{array}$ & $\begin{array}{l}57 \\
96 \\
92 \\
55\end{array}$ & $\begin{array}{l}13 \\
24 \\
22 \\
11\end{array}$ & $\begin{array}{l}-220 \\
+413 \\
-361 \\
-34\end{array}$ & $\begin{array}{l}-13 \\
-1 \\
-4 \\
-13\end{array}$ & $\begin{array}{r}-1 \\
+3 \\
-3 \\
0\end{array}$ \\
\hline Mujeres & & & & & 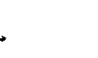 & & & & \\
\hline $\begin{array}{lllllllll}\operatorname{Total} & \ldots & \ldots & \ldots & \ldots & \ldots & \ldots & \ldots & \ldots\end{array}$ & 3.801 & 32 & 29 & 3.957 & 32 & 30 & +156 & 0 & +1 \\
\hline $\begin{array}{lllllllllll}15-24 \text { años } & \ldots & \ldots & \ldots & \ldots & \ldots & \ldots & \ldots & \ldots & \ldots \\
25-39 \text { años } & \ldots & \ldots & \ldots & \ldots & \ldots & \ldots & \ldots & \ldots & \ldots \\
40-54 \text { años } & \ldots & \ldots & \ldots & \ldots & \ldots & \ldots & \ldots & \ldots & \ldots \\
55-69 \text { años } & \ldots & \ldots & \ldots & \ldots & \ldots & \ldots & \ldots & \ldots & \ldots \\
5\end{array}$ & $\begin{array}{r}1.342 \\
891 \\
1.010 \\
558\end{array}$ & $\begin{array}{l}52 \\
30 \\
29 \\
21\end{array}$ & $\begin{array}{r}10 \\
7 \\
8 \\
4\end{array}$ & $\begin{array}{r}1.233 \\
1.363 \\
889 \\
472\end{array}$ & $\begin{array}{l}46 \\
41 \\
27 \\
15\end{array}$ & $\begin{array}{r}9 \\
10 \\
7 \\
4\end{array}$ & $\begin{array}{l}-109 \\
+472 \\
-121 \\
-86\end{array}$ & $\begin{array}{r}-6 \\
+11 \\
-2 \\
-6\end{array}$ & $\begin{array}{r}-1 \\
+3 \\
-1 \\
0\end{array}$ \\
\hline
\end{tabular}

FUENTES: EPA del INE, 2..$^{\circ}$ semestre 1974 y $4 .^{\circ}$ trimestre 1984. En el año 1984, el primer grupo de edad es de 16-24 años. Elaboración propia. Cifras redondeadas. 
tal posibilidad conviene atender a los datos no ya de población activa, sino ahora de población ocupada.

Pues bien, las cifras registradas en el cuadro 2, correspondientes a la misma evolución temporal pero referidas ahora a la población ocupada, reflejan exactamente la misma tendencia, premiadora de las posiciones adultas y castigadora de las posiciones juveniles y ancianas: la única diferencia, respecto a las cifras correspondientes a la población activa, consiste en que la tendencia discriminadora aparece aquí mucho más intensamente entre las mujeres que entre los hombres. En cualquier caso, dejando de lado este incontestable triunfo del feminismo adulto (a costa de la derrota del feminismo juvenil o anciano), cabe advertir que son los crecientemente escasos adultos, sea cual fuere su sexo, quienes mejoran muy mucho su participación en la población ocupada: tanto en cifras absolutas (pues si bien los varones adultos disminuyen su ocupación, lo hacen, sin embargo, en muchísima menor medida que los jóvenes o los maduros; las mujeres adultas, por su parte, incluso en esta época de destrucción del empleo, incrementan sensiblemente el número total de empleos que ocupan, tanto que su ascenso es superior a la pérdida experimentada por los varones coetáneos, con lo que el total de ambos sexos, para esa edad, ve cómo sus cifras de empleo se incrementan, en plena crisis económica) como en relativas (sea en tasas o sea en cuotas, los adultos y las adultas mejoran muy mucho las posiciones ocupadas, a costa, por descontado, de las gigantescas pérdidas experimentadas por los jóvenes y las personas maduras). En definitiva, la evolución de la distribución por edades del mercado de trabajo ha sido contracíclica respecto a su equivalente demográfico, pues la tendencia sufrida por la pirámide poblacional (reducción del número de adultos, incremento del número de jóvenes y del de ancianos) ha sido estrictamente inversa a la experimentada por la pirámide ocupacional (incremento del número de adultos, fortísima reducción del número de jóvenes y del de ancianos). ¿Cómo negar, entonces, que ello tenga algo que ver con las modificaciones sufridas por el índice de Easterlin (razón del número de adultos al número de jóvenes), que no es sino la expresión numérica cuantificadora de una relación social: la relación social mutua y recíprocamente contraída por los adultos y los jóvenes? ${ }^{8}$.

\section{La evolución reciente de la juventud española}

Las actuales desgracias de la juventud y la ancianidad son, por tanto, resultado de la contradictoria evolución de las pirámides poblacional y ocupa-

${ }^{8}$ R. A. Easterlin, Population, Labour Force and Long Swings in Economic Growth, Nueva York, National Bureau of Economic Research, 1968; "What will 1984 be like? Socioeconomics implications of recent twists in age structuresm, en Demography, vol. 15, núm. 4, 1978, pp. 397.432; «Demographic Influences on Economic Stability. The United States Experience», en Population and Development Review, marzo 1978, pp. 1-22. 


\section{CUADRO 2}

La evolución de la población ocupada española, de 1974 a 1984

\begin{tabular}{|c|c|c|c|c|c|c|c|c|c|}
\hline & \multicolumn{3}{|c|}{ AÑo 1974} & \multicolumn{3}{|c|}{ AÑo 1984} & \multicolumn{3}{|c|}{ Diferenciales $74-84$} \\
\hline & $\begin{array}{c}\text { Ocupados } \\
\text { (miles) }\end{array}$ & $\begin{array}{c}\text { Tasas } \\
(\%)\end{array}$ & $\begin{array}{c}\text { Cuotas } \\
(\%)\end{array}$ & $\begin{array}{c}\text { Ocupados } \\
\text { (miles) }\end{array}$ & $\begin{array}{c}\text { Tasas } \\
(\%)\end{array}$ & $\begin{array}{c}\text { Cuotas } \\
\text { (\%) }\end{array}$ & $\begin{array}{c}\text { Ocupados } \\
\text { (miles) }\end{array}$ & $\begin{array}{c}\text { Tasas } \\
(\%)\end{array}$ & $\begin{array}{c}\text { Cuotas } \\
(\%)\end{array}$ \\
\hline \multicolumn{10}{|l|}{ Ambos sexos } \\
\hline $\begin{array}{lllllllll}\text { Total } & \ldots & \ldots & \ldots & \ldots & \ldots & \ldots & \ldots & \ldots\end{array}$ & 12.832 & 56 & 100 & 10.292 & 42 & 100 & -2.540 & -14 & 0 \\
\hline $\begin{array}{lllllllllll}15-24 \text { años } & \ldots & \ldots & \ldots & \ldots & \ldots & \ldots & \ldots & \ldots & \ldots \\
25-39 \text { años } & \ldots & \ldots & \ldots & \ldots & \ldots & \ldots & \ldots & \ldots & \ldots \\
40-54 \text { años } & \ldots & \ldots & \ldots & \ldots & \ldots & \ldots & \ldots & \ldots & \ldots \\
55-69 \text { años } & \ldots & \ldots & \ldots & \ldots & \ldots & \ldots & \ldots & \ldots & \ldots\end{array}$ & $\begin{array}{l}3.037 \\
3.563 \\
4.188 \\
2.044\end{array}$ & $\begin{array}{l}57 \\
62 \\
61 \\
41\end{array}$ & $\begin{array}{l}24 \\
28 \\
32 \\
16\end{array}$ & $\begin{array}{l}1.487 \\
3.682 \\
3.371 \\
1.752\end{array}$ & $\begin{array}{l}26 \\
56 \\
53 \\
30\end{array}$ & $\begin{array}{l}14 \\
36 \\
33 \\
17\end{array}$ & $\begin{array}{r}-1.550 \\
+\quad 119 \\
-\quad 817 \\
-\quad 292\end{array}$ & $\begin{array}{l}-31 \\
-6 \\
-8 \\
-11\end{array}$ & $\begin{array}{l}-10 \\
+8 \\
+1 \\
+1\end{array}$ \\
\hline \multicolumn{10}{|l|}{ Varones } \\
\hline $\begin{array}{lllllllll}\text { TOtal } & \ldots & \ldots & \ldots & \ldots & \ldots & \ldots & \ldots & \ldots\end{array}$ & 9.148 & 82 & 71 & 7.332 & 61 & 71 & -1.816 & -21 & 0 \\
\hline $\begin{array}{lllllllllll}15-24 & \text { años } & \ldots & \ldots & \ldots & \ldots & \ldots & \ldots & \ldots & \ldots & \ldots \\
25-39 \text { años } & \ldots & \ldots & \ldots & \ldots & \ldots & \ldots & \ldots & \ldots & \ldots \\
40-54 \text { años } & \ldots & \ldots & \ldots & \ldots & \ldots & \ldots & \ldots & \ldots & \ldots \\
55-69 & \text { años } & \ldots & \ldots & \ldots & \ldots & \ldots & \ldots & \ldots & \ldots & \ldots\end{array}$ & $\begin{array}{l}1.775 \\
2.688 \\
3.196 \\
1.489\end{array}$ & $\begin{array}{l}65 \\
95 \\
95 \\
66\end{array}$ & $\begin{array}{l}14 \\
21 \\
24 \\
12\end{array}$ & $\begin{array}{r}891 \\
2.590 \\
2.547 \\
1.304\end{array}$ & $\begin{array}{l}30 \\
79 \\
81 \\
48\end{array}$ & $\begin{array}{r}8 \\
25 \\
25 \\
13\end{array}$ & $\begin{array}{l}-\quad 884 \\
-\quad 98 \\
-\quad 649 \\
-\quad 185\end{array}$ & $\begin{array}{l}-35 \\
-16 \\
-14 \\
-18\end{array}$ & $\begin{array}{l}-6 \\
+4 \\
+1 \\
+1\end{array}$ \\
\hline \multicolumn{10}{|l|}{ Mujeres } \\
\hline $\begin{array}{lllllllll}\operatorname{Total} & \ldots & \ldots & \ldots & \ldots & \ldots & \ldots & \ldots & \ldots\end{array}$ & 3.684 & 31 & 29 & 2.960 & 24 & 29 & -724 & -7 & 0 \\
\hline $\begin{array}{lllllllllll}15-24 & \text { años } & \ldots & \ldots & \ldots & \ldots & \ldots & \ldots & \ldots & \ldots & \ldots \\
25-39 \text { años } & \ldots & \ldots & \ldots & \ldots & \ldots & \ldots & \ldots & \ldots & \ldots \\
40-54 \text { años } & \ldots & \ldots & \ldots & \ldots & \ldots & \ldots & \ldots & \ldots & \ldots \\
55-69 \text { años } & \ldots & \ldots & \ldots & \ldots & \ldots & \ldots & \ldots & \ldots & \ldots & \ldots \\
\end{array}$ & $\begin{array}{r}1.262 \\
875 \\
992 \\
555\end{array}$ & $\begin{array}{l}49 \\
30 \\
28 \\
20\end{array}$ & $\begin{array}{r}10 \\
7 \\
8 \\
4\end{array}$ & $\begin{array}{r}596 \\
1.092 \\
824 \\
448\end{array}$ & $\begin{array}{l}22 \\
33 \\
25 \\
15\end{array}$ & $\begin{array}{r}6 \\
11 \\
8 \\
4\end{array}$ & $\begin{array}{l}-\quad 666 \\
+\quad 217 \\
-\quad 168 \\
-\quad 107\end{array}$ & $\begin{array}{l}-27 \\
+3 \\
-3 \\
-5\end{array}$ & $\begin{array}{r}-4 \\
+4 \\
0 \\
0\end{array}$ \\
\hline
\end{tabular}

FUENTES: EPA del INE, 2. semestre 1974 y $4 .^{\circ}$ trimestre 1984. En el año 1984, el primer grupo de edad es de 16-24 años. Elaboración propia. Cifras redondeadas. 
cional: mientras la pirámide poblacional ha evolucionado en el sentido de incrementar extraordinariamente el número absoluto y relativo de jóvenes (así como el de ancianos, esto es evidente), la pirámide ocupacional, por el contrario, lo ha hecho en el sentido de reducir, también extraordinariamente, el número absoluto y relativo de empleos ocupados por los jóvenes (así como por los ancianos, naturalmente). De tal modo, emparedados entre estas dos contradictorias evoluciones temporales, los jóvenes han ido viendo cómo sus condiciones de vida, luego sus conductas, se iban modificando extraordinariamente (así como las de los ancianos, y por las mismas razones; pero de su problema no puedo ocuparme aquí).

Tal brutal modificación de las condiciones de vida en que se desenvuelven las conductas de los jóvenes puede ser analizada mediante las cifras que aparecen en el cuadro 3, donde se cuantifica la evolución, desde 1964 hasta 1984, de los principales indicadores susceptibles de describir la conducta juvenil: sus tasas de ocupación, desempleo, escolaridad e inactividad (expresadas en porcentajes sobre los respectivos totales poblacionales de cada grupo de edad y sexo, razón por la que dichas tasas son sumables hasta abarcar el 100 por 100 de cada grupo de sexo y edad). Y estas cifras son tan violentamente significativas que su desnuda contemplación impone el pudor de ahorrar comentarios.

Una cosa sí puede decirse: si la juventud española de 1964 podía ser calificada, sin temor a errores, como «juventud obrera» (ya que seis de cada diez jóvenes menores de 20 se hallaban trabajando), de ninguna manera puede ya decirse lo mismo en 1984 (ya que sólo dos de cada diez jóvenes menores de 20 se encuentran trabajando). Hoy, con voluntad o sin ella, los jóvenes españoles se hallan situados a espaldas del mundo del trabajo, cuya puerta de entrada guardan los adultos celosamente cerrada.

¿Y qué es lo que significa eso? Entre muchas otras cosas, que, como carecen de jornada laboral, los jóvenes disponen de abrumadores excedentes temporales que no saben cómo invertir. El cuadro 4 lo registra con todo cuidado: en tan sólo diez años, justo desde que se inicia la crisis económica, la jornada laboral de los jóvenes (es decir, el promedio de minutos diarios que dedican al trabajo la totalidad de los jóvenes, sumándose en el promedio tanto los que sí trabajan como los que no) ha quedado reducida casi a la mitad. Por tanto, si el tiempo de trabajo se ha reducido tanto, las otras clases de tiempo -de satisfacción de necesidades físicas, como dormir, comer, asearse o genitalizar; de trabajo doméstico; de estudio, $o$, en fin, de ocio- tendrán forzosamente que haberse incrementado, $y$, en efecto, así ha sido, como puntualmente registra el cuadro 4 (donde las series son comparables por estar obtenidas con idéntica metodología - la de timebudget-, no habiendo sido posible encontrar series comparables para el 64), especialmente por lo que hace al tiempo de estudio y al tiempo de ocio (objeto este último en el que me centraré algo). 
CUADRO 3

La evolución de la juventud española, de 1964 a 1984

Ambos sexos

Total $15-64 \ldots \ldots \ldots \ldots$

\begin{tabular}{|c|c|c|c|}
\hline \multicolumn{4}{|c|}{ AÑo 1964} \\
\hline $\begin{array}{c}\text { Tasa } \\
\text { ocup. } \\
\text { (A) } \\
\%\end{array}$ & $\begin{array}{l}\text { Tasa } \\
\text { des. } \\
\text { (B) } \\
\%\end{array}$ & $\begin{array}{l}\text { Tasa } \\
\text { esc. } \\
\text { (C) } \\
\text { or }\end{array}$ & $\begin{array}{c}\text { Tasa } \\
\text { inac. } \\
\text { (D) } \\
\%\end{array}$ \\
\hline
\end{tabular}

\begin{tabular}{|c|c|c|c|}
\hline & Ā̃o & 1974 & \\
\hline $\begin{array}{c}\text { Tasa } \\
\text { ocup. } \\
\text { (A) } \\
\%\end{array}$ & $\begin{array}{l}\text { Tasa } \\
\text { des. } \\
\text { (B) } \\
\%\end{array}$ & $\begin{array}{l}\text { Tasa } \\
\text { esc. } \\
\text { (C) } \\
\%\end{array}$ & $\begin{array}{c}\text { Tasa } \\
\text { inac. } \\
\text { (D) } \\
\%\end{array}$ \\
\hline
\end{tabular}

\begin{tabular}{cccc} 
& AÑo & 1984 & \\
\hline Tasa & Tasa & Tasa & Tasa \\
ocup. & des. & esc. & inac. \\
(A) & (B) & (C) & (D) \\
$\%$ & $\%$ & $\%$ & $\%$ \\
\hline
\end{tabular}

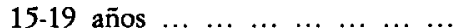

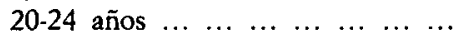

$\begin{array}{rrr}56 & 1 & 4 \\ 54 & 2 & 22 \\ 61 & 2 & 8 \\ 58 & 1 & 1 \\ 55 & 1 & -\end{array}$

39
22
29
40
44

$\begin{array}{rrr}58 & 2 & 7 \\ 48 & 5 & 38 \\ 67 & 4 & 14 \\ 63 & 2 & 3 \\ 58 & 1 & -\end{array}$

33
9
15
32
41

$\begin{array}{rrrr}45 & 13 & 8 & 34 \\ 18 & 24 & 50 & 8 \\ 37 & 30 & 20 & 13 \\ 54 & 19 & 3 & 24 \\ 50 & 6 & - & 44\end{array}$

Varones

Total $15-64 \ldots \ldots \ldots$

$\begin{array}{llr}89 & 2 & 5 \\ 69 & 4 & 26 \\ 83 & 3 & 12 \\ 94 & 2 & 2 \\ 93 & 2 & -\end{array}$

4
1
2
2
5

$\begin{array}{rrr}84 & 3 & 8 \\ 53 & 6 & 40 \\ 78 & 5 & 16 \\ 91 & 3 & 4 \\ 91 & 2 & -\end{array}$

5
1
1
2
7

$\begin{array}{rrrr}65 & 17 & 9 & 9 \\ 21 & 27 & 49 & 3 \\ 45 & 33 & 20 & 2 \\ 71 & 23 & 3 & 3 \\ 76 & 11 & - & 13\end{array}$

Mujeres

Total $15-64 \ldots \ldots \ldots \ldots$

\begin{tabular}{rrrrrrrrrrrr}
25 & 1 & 3 & 71 & 33 & 1 & 6 & 60 & 25 & 9 & 8 & 58 \\
38 & 1 & 17 & 44 & 43 & 4 & 36 & 17 & 14 & 20 & 51 & 15 \\
43 & 1 & 4 & 52 & 55 & 3 & 11 & 31 & 30 & 26 & 21 & 23 \\
26 & - & - & 74 & 35 & 1 & 1 & 63 & 38 & 14 & 3 & 45 \\
20 & - & - & 80 & 27 & - & - & 73 & 25 & 2 & - & 73 \\
\hline
\end{tabular}

$\begin{array}{llllllll}15-19 & \text { años } & \ldots & \ldots & \ldots & \ldots & \ldots & \ldots\end{array}$

20-24 años

25-29 años

(A) Tasa de ocupación: porcentaje de ocupados sobre el total poblacional de cada grupo de edad y sexo.

(B) Tasa de desempleo: porcentaje de desempleados sobre el total poblacional de cada grupo de edad y sexo.

(C) Tasa de escolaridad: porcentaje de estudiantes sobre el total poblacional de cada grupo de edad y sexo.

(D) Tasa de inactividad: porcentaje de "resto de inactivos" (amas de casa dedicadas a "sus labores", jubilados, incapacitados, internados en instituciones cerradas, etc.) sobre el total poblacional de cada grupo de edad y' sexo.

Nota: Las cuatro tasas (A, B, C y D), sumadas para cada año y cada grupo de edad y sexo, deben alcanzar el 100 por 100 del total poblacional de cada grupo de edad y sexo. Cifras redondeadas.

FuENTES: EPA del INE, 4.० trimestre 1964, 2.0 semestre 1974 y $4 .^{\circ}$ trimestre 1984 . En los tres casos se ha excluido el contingente masculino que presta el servicio militar. En el año 1984, el primer grupo de edad es de 16 a 19 años (en lugar de ser de 15 a 19 como en el resto). Elaboración propia. 


\section{CUADRO 4}

El ocio de la juventud española en 1984: su evolución desde 1973

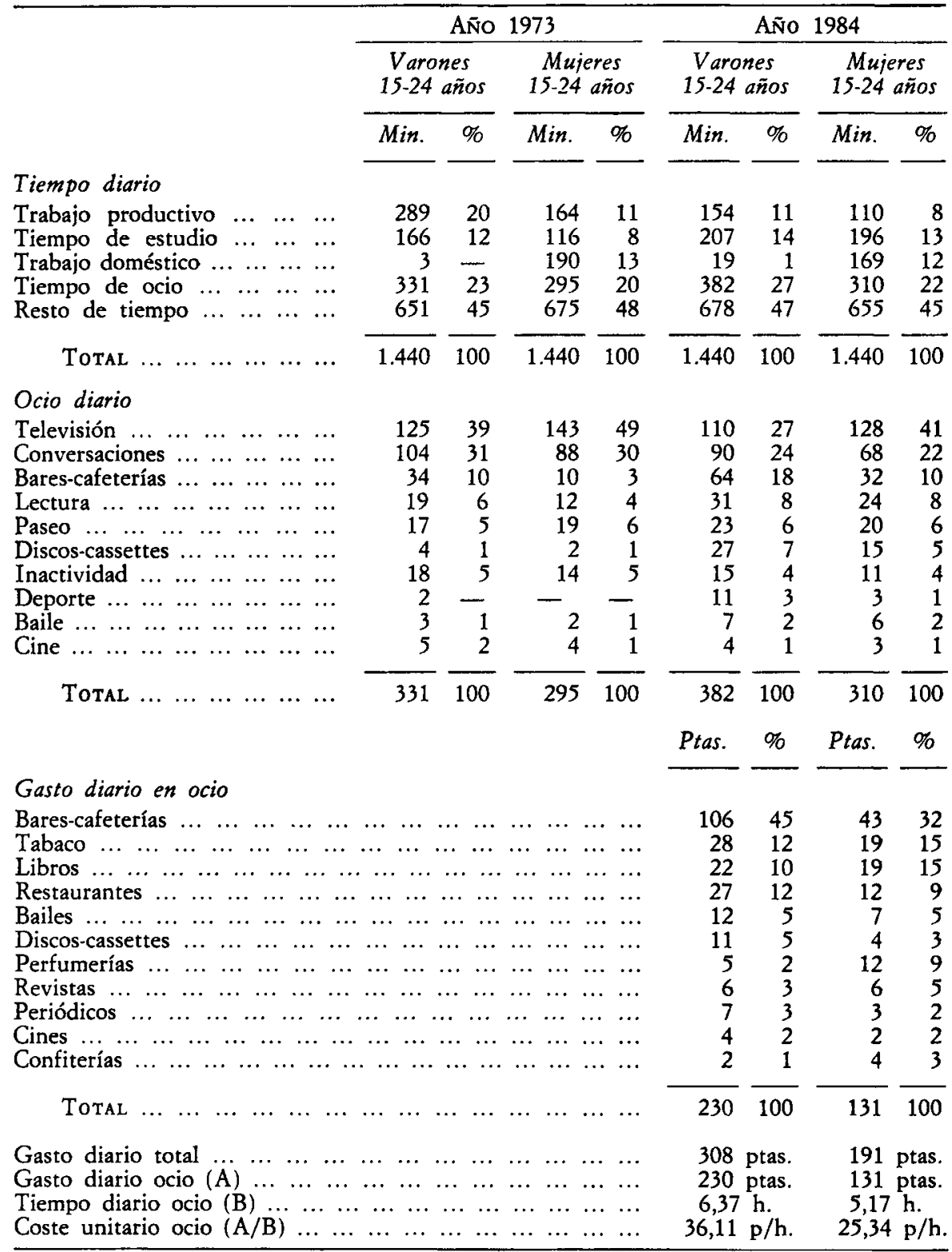

Fuentes: Para el 73, Visedo, Zárraga y Barrio, El empleo del tiempo de la población española, Gabinete de Investigación de Audiencia de RTVE, 1976; para el 84, José Luis ZárRaGa, Empleo del tiempo y recursos económicos de los jóvenes españoles, Ministerio de Cultura. 
En todo caso, y puesto que los datos del cuadro 4 aparecen desagregados por sexo, resulta posible analizar diferencialmente la evolución temporal de la juventud española. $Y$, en efecto, de forma coherente con cuanto vimos en los cuadros 1, 2 y 3 (en los que resultaba probado que los jóvenes varones perdían tasa y cuota de actividad y ocupación en mucha mayor medida que las mujeres jóvenes, quienes, además de ello, reducían fuertemente su tasa de inactividad - «sus labores»- e incrementaban su tasa de escolaridad en muchísima mayor medida que los hombres), en el cuadro 4 puede advertirse que en estos diez años de crisis económica, entre el 73 y el 84, las chicas jóvenes han evolucionado más intensamente que los chicos: no han reducido tanto su tiempo de trabajo y han incrementado más su tiempo de estudio; además, y como prueba supletoria del proceso de modernización experimentado por la juventud española (mayores niveles de escolarización, de secularización, de lectura, etc.), advertiremos, por el cuadro 4 , que se ba reducido la desigualdad entre los sexos (cosa que ya podía advertirse en el cuadro 3, donde, partiendo de tasas enormemente desiguales en 1964, se llegaba a tasas prácticamente idénticas entre chicos y chicas en 1984).

En efecto, una de las dos causas fundamentales de la discriminación de la mujer (la otra es la desigualdad ocupacional) es la diferencial distribución en función del sexo del trabajo doméstico: a las mujeres se les obliga a invertir una octava parte de su tiempo trabajando para el hogar, cosa que no se exige a los hombres. Pues bien, en el cuadro 4 advertiremos que tal desigualdad, aunque subsiste muy pronunciada, sin embargo, se ha reducido sensiblemente en estos diez años de crisis modernizadora: los chicos han multiplicado por seis su ración de trabajo doméstico, mientras que las chicas la han reducido un 12 por 100; dicho de otro modo, en 1973 las chicas trabajaban en el hogar durante un tiempo que era 63 veces mayor que el de los chicos, mientras que en 1984 las chicas trabajaban en casa durante un tiempo sólo 9 veces mayor que el de los chicos. Algo es algo, aunque, en términos relativos, la desigualdad en el tiempo dedicado al trabajo doméstico sigue siendo desfavorable a las chicas en una relación de 12 a 1 . Pero aunque la discriminación siga ahí, plenamente vigente, la situación de las chicas se ha modernizado muchísimo: esta disminución en su jornada de trabajo doméstico debe ser relacionada con la gigantesca disminución de las tasas de dedicación a «sus labores» que veíamos en el cuadro 3 (entre el 64 y el 84, las chicas de 15 a 19 pasaban del 44 por 100 de «sus labores» al 15 por 100 ; las de 20 a 24 años, de un 52 a un 23 por 100 , y las de 25 a 29 años, de un 74 a un 45 por 100).

¿Qué consecuencias cabe extraer de esta brutal disminución del trabajo doméstico femenino? Que es, fundamentalmente, debido a la caída imparable de la fecundidad. Como las chicas ya no pueden dedicarse a la crianza de niños, reducen fuertemente sus tasas de «sus labores» y reducen fuertemente su tiempo de trabajo doméstico, reducciones cuyas disponibilidades exceden- 
tarias son, a su vez, reinvertidas en incrementar las tasas de escolaridad y actividad y en incrementar el tiempo de estudio y el tiempo de ocio (como prueban los cuadros 3 y 4 ).

\section{Breve estudio del ocio juvenil español}

La evolución reciente de la pirámide poblacional ha incrementado intensamente el número de jóvenes en términos tanto absolutos como relativos. Simultáneamente, la evolución reciente de la pirámide ocupacional ha reducido intensamente el número de empleos ocupados por los jóvenes tanto en términos absolutos como relativos. Estos dos factores contradictorios, al combinarse mutuamente, han producido como consecuencia ineludible un gigantesco crecimiento del montante global de tiempo de ocio disponible por los jóvenes españoles: estudiantes, parados, ociosos, vagabundos, pasotas, drogadictos, delincuentes, desviados y marginales, son algunos de los rótulos bajo los que públicamente se conoce este fenómeno del imparable crecimiento del ocio juvenil. ¿Qué hacer con el creciente ocio de los jóvenes, cuya magnitud absoluta seguirá creciendo imparablemente —aunque la relativa se estabilicehasta por lo menos 1992? Antes de tomar decisiones relativas al ocio juvenil conviene conocerlo algo mejor ${ }^{9}$.

En los cuadros 4, 5, 6, 9 y 10 aparecen cuantificados datos relativos al ocio de los jóvenes en función de distintas desagregaciones; tales datos aparecen ordenados en dos series que componen las dos dimensiones objetivas ${ }^{10}$ fundamentales para la definición del ocio: el tiempo y el dinero que en él se invierte.

Respecto al cuadro 4 , conviene advertir inmediatamente el intenso proceso de modernización que, en tan sólo diez años, ha experimentado el ocio juvenil español. En 1973, el ocio de los jóvenes españoles era todavía francamente tercermundista, distribuido en régimen de monocultivo conversacional-televisivo (los dos ocios menos costosos: mirar TV y charlar con amigos; aquellos ocios para los que los jóvenes no precisan recursos). En 1984, por el contrario, el ocio juvenil español aparece mucho más variado, equilibrado y diversi-

${ }^{9}$ Lo que sigue a continuación es un resumen esquemático de los capítulos 2 y 3 del libro de E. Gil Calvo y E. Menéndez Vergara, Ocio y prácticas culturales de los jóvenes, Madrid, Instituto de la Juventud, Ministerio de Cultura, 1985, pp. 44-149.

10 La mayor parte de las encuestas sobre comportamiento cultural no consisten, en definitiva, más que en estudios de opinión: a los encuestados se les interroga sobre la percepción subjetiva que confiesan acerca de su propia conducta. Tales métodos son mínimamente fiables. Aquí, y en el libro del que estas páginas no son más que breve resumen, se sigue otra metodología completamente distinta, basada en la perspectiva "etic" de Marvin Harris (véase su libro Materialismo cultural, Madrid, Alianza Universidad, 1982, pp. 44 a 61). Por ello, las fuentes de datos utilizadas consisten en cuantificaciones objetivas de la conducta, obtenidas mediante la técnica del "recuerdo de la víspera» y estructuradas en forma de time budget. El diseño y la dirección corrieron a cargo de José Luis Zárraga. 
ficado: mucha menos TV y conversación frente a mucha más lectura, música y deporte. Dado que tales actividades precisan mayores recursos materiales, cabe concluir que el ocio de los jóvenes españoles se ha enriquecido bastante (carezco de datos sobre gasto en ocio para 1973 cuya metodología sea comparable). Y ello plantea la paradoja siguiente. Como veremos a continuación, son los parados y los estudiantes (los económicamente dependientes) quienes disponen de un ocio más pobre, frente a los ocupados y económicamente independientes, que son quienes disponen de un ocio más rico. Pues bien, entre 1973 y 1984, el porcentaje de estudiantes y parados se ha incrementado mucho, mientras que, a la vez, el porcentaje de ocupados ha disminuido bastante: luego el ocio global debería de haberse empobrecido, en lugar de enriquecerse.

Existe una posible explicación institucionalista. En estos diez años, además de la crisis económica, se ha producido en España un proceso de cambio político (muerte del franquismo, transición jurídico-política, sustitución generacional de élites dirigentes, consolidación de la democracia, etc.), cuya consecuencia sociológica ha sido la aceleración del proceso de modernización y secularización de la sociedad española. La modernización y enriquecimiento del ocio juvenil sería otro efecto indirecto de ese mismo proceso de cambio institucional y político.

Pero hay otras posibles explicaciones ya no institucionalistas, sino materialistas. Por ejemplo, la siguiente. En estos diez años de crisis económica, la renta familiar disponible se ha mantenido estable (creció desde 1973 hasta 1979, se estabilizó entre 1980 y 1981 y empezó a descender a partir de 1982, sin que todavía haya bajado hasta el nivel del 73). Pero, simultáneamente, la tasa de dependencia se ha elevado enormemente, lo que implica que esa renta familiar estable ha sido obtenida cada vez por menos personas, pero repartida cada vez entre más. A nuestros efectos, el resultado ha sido el siguiente: las rentas salariales de los adultos ocupados han crecido mucho, pero también lo ha hecho, compensatoriamente, el número de hijos parados dependientes de esos adultos asalariados; como los padres han venido ganando más pero han tenido que mantener desocupados a más hijos durante más tiempo, la renta familiar ha permanecido estable.

¿A costa de qué? Esta monopolización del trabajo por los adultos, y la consiguiente exclusión de los hijos del trabajo, ha costado un precio. La paz familiar se ha conseguido mediante la transferencia monetaria desde los padres monopolizadores hasta los hijos dependientes excluidos del mercado de trabajo. Es decir, los adultos, para impedir la entrada de los jóvenes al mercado de trabajo, han tenido que comprarles: sobornarles para que estén contentos, con su desocupación, y no protesten ni se rebelen. ¿De dónde ha salido el dinero de semejante soborno? De la inflación salarial, que ha posibilitado el que, a pesar del soborno, la renta familiar permanezca estable. ¿Y adónde ha ido el dinero del soborno? A sufragar los gastos crecientes de los jóvenes de- 
pendientes (parados, estudiantes, desocupados, es lo mismo), es decir, a sufragarles un ocio costoso para evitar que protesten y exijan independencia económica. Es por esto por lo que, a pesar de ser mucho más dependientes económicamente que en 1973 (ya que ahora trabajan muchos menos que entonces), los jóvenes de 1984 gastan en ocio muchísimo más que entonces: porque su ocio de parados permanentes se lo subvenciona la mala conciencia de sus sindicados padres monopolizadores.

Pero volvamos al análisis de los datos relativos al ocio juvenil. Antes de comentar los cuadros 5 y 6 conviene volver, una vez más, al cuadro 4: allí aparecen desagregados en función del sexo tanto los tiempos como los gastos invertidos en ocio. El que las chicas tengan menos tiempo de ocio que los chicos, a pesar de tener también menos tiempo de trabajo, es debido a que las chicas tienen muchísimo más tiempo de trabajo doméstico que los chicos. Ahora bien, ese menor tiempo de ocio las chicas lo invierten más pobremente que los chicos: viendo TV sobre todo. ¿Por qué? Las cifras de gasto en ocio nos proporcionan la razón. Las chicas pueden gastar en ocio muchísimo menos dinero que los chicos (ya sea debido a que trabajan menos que los chicos, ya sea debido a que obtienen menores ingresos que los chicos por los mismos trabajos, o ya sea debido a que reciben mucho menos dinero de sus padres que los chicos, a pesar de correr por cuenta de ellas casi todo el trabajo familiar-doméstico); por ello, al carecer de recursos materiales, deben concentrar su tiempo en ocios poco costosos, es decir, en TV sobre todo. Esta pauta que acabamos de ver relacionada con el sexo será la que volvamos a encontrar cuando analicemos los cuadros 5, 6, 9 y 10: aquellas categorías juveniles que dispongan de menores recursos materiales (medibles por sus índices de gasto en ocio) serán las que se vean obligadas a invertir su tiempo disponible en los ocios menos costosos de todos, en TV sobre todo; en cambio, aquellas categorías juveniles que dispongan de mayores recursos materiales, o de niveles más altos de gasto diario en ocio, serán las que puedan permitirse el lujo de invertir su tiempo de ocio en actividades más variadas, equilibradas y diversificadas, como bares y restaurantes, lectura y música, etc. Por tanto, y volviendo al sexo como variable discriminatoria, no es que exista un menú «femenino» de ocio, centrado en la televisión, y otro menú «masculino", centrado en la música y los bares, sino que se trata de que los recursos materiales están desigualmente repartidos en función del sexo (como prueban las cifras del cuadro 10), y como las chicas son más pobres que los chicos, deben resignarse a quedarse en casa viendo TV (porque las que, como las chicas liberadas del cuadro 10 , disponen de independencia económica, se lanzan a la calle y apagan el televisor).

En los cuadros 5 y 6 aparecen los datos relativos al ocio juvenil (tiempo y gasto diarios invertidos) desagregados en función de la actividad (en el cuadro 5 se incluye también el promedio global correspondiente a la totalidad de la juventud). Podrá inmediatamente advertirse que son los parados y pa- 


\section{CUADRO 5}

El ocio de la juventud española en 1984: total y varones según actividad

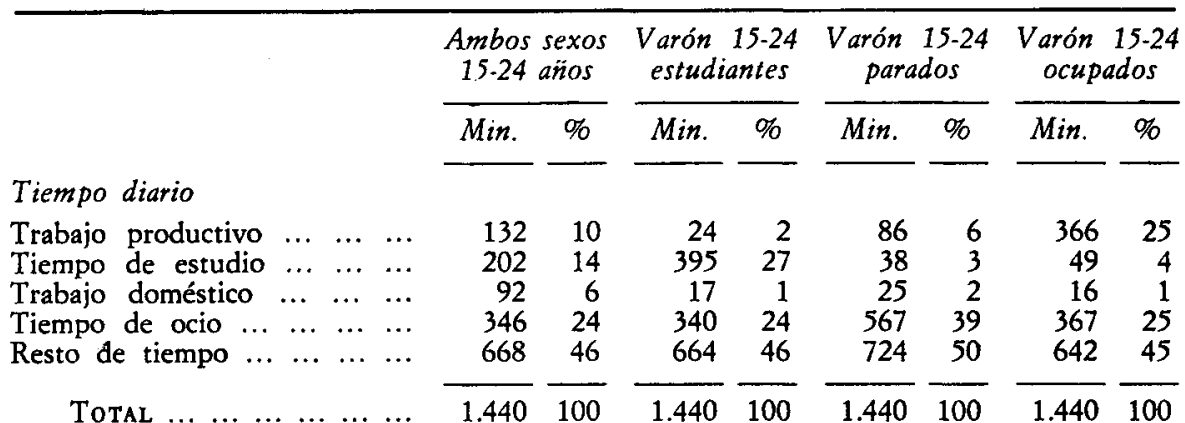

\section{Ocio diario}

\begin{tabular}{|c|c|c|c|c|c|c|c|c|c|}
\hline \multirow{12}{*}{\multicolumn{2}{|c|}{ 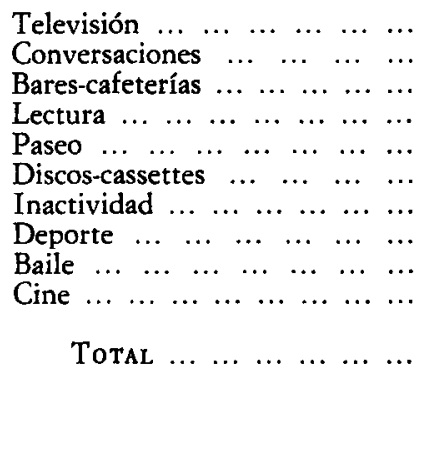 }} & \multirow{10}{*}{$\begin{array}{r}119 \\
79 \\
49 \\
28 \\
21 \\
20 \\
13 \\
7 \\
6 \\
4\end{array}$} & \multirow{10}{*}{$\begin{array}{r}34 \\
23 \\
14 \\
8 \\
6 \\
6 \\
4 \\
2 \\
2 \\
1\end{array}$} & \multirow{10}{*}{$\begin{array}{r}106 \\
63 \\
62 \\
30 \\
18 \\
27 \\
12 \\
13 \\
3 \\
6\end{array}$} & \multirow{10}{*}{$\begin{array}{r}31 \\
19 \\
18 \\
9 \\
5 \\
8 \\
4 \\
4 \\
1 \\
1\end{array}$} & \multirow{10}{*}{$\begin{array}{r}143 \\
148 \\
103 \\
37 \\
45 \\
35 \\
29 \\
12 \\
13 \\
2\end{array}$} & \multirow{10}{*}{$\begin{array}{r}25 \\
26 \\
18 \\
7 \\
8 \\
6 \\
5 \\
2 \\
2 \\
1\end{array}$} & \multirow{10}{*}{$\begin{array}{r}98 \\
94 \\
76 \\
29 \\
19 \\
20 \\
9 \\
7 \\
9 \\
6\end{array}$} & \multirow{10}{*}{$\begin{array}{r}27 \\
26 \\
21 \\
8 \\
5 \\
5 \\
2 \\
2 \\
2 \\
2\end{array}$} \\
\hline & & & & & & & & & \\
\hline & & & & & & & & & \\
\hline & & & & & & & & & \\
\hline & & & & & & & & & \\
\hline & & & & & & & & & \\
\hline & & & & & & & & & \\
\hline & & & & & & & & & \\
\hline & & & & & & & & & \\
\hline & & & & & & & & & \\
\hline & & 346 & 100 & 340 & 100 & 567 & 100 & 367 & 100 \\
\hline & & Ptas. & $\%$ & Pias. & $\%$ & Ptas. & $\%$ & Ptas. & $\%$ \\
\hline \multicolumn{10}{|l|}{ Gasto diario en ocio } \\
\hline $\begin{array}{lllll}\text { Bares-cafeterías } & \ldots & \ldots & \ldots & \text {. }\end{array}$ & ... & 75 & 42 & 65 & 41 & 138 & 54 & 144 & 46 \\
\hline $\begin{array}{lllllll}\text { Tabaco } & \ldots & \ldots & \ldots & \ldots & \ldots & \ldots \\
\text {. }\end{array}$ & $\ldots$ & 24 & 13 & 17 & 11 & 37 & 15 & 38 & 12 \\
\hline $\begin{array}{lllllll}\text { Libros } & \ldots & \ldots & \ldots & \ldots & \ldots & \ldots\end{array}$. & $\ldots$ & 20 & 11 & 28 & 18 & 5 & 2 & 23 & 7 \\
\hline $\begin{array}{lllllll} & \\
\text { Restaurantes } & \ldots & \ldots & \ldots & \ldots & \end{array}$ & $\ldots$ & 20 & 11 & 16 & 10 & 12 & 5 & 50 & 16 \\
\hline $\begin{array}{llllllll}\text { Bailes } & \ldots & \ldots & \ldots & \ldots & \ldots & \ldots & \end{array}$ & $\ldots$ & 10 & 5 & 6 & 4 & 19 & 8 & 16 & 5 \\
\hline $\begin{array}{lllll}\text { Discos-cassettes } & \ldots & \ldots & \ldots & \text {. }\end{array}$ & $\ldots$ & 8 & 4 & 7 & 4 & 24 & 10 & 10 & 3 \\
\hline Perfumerías ... & $\ldots$ & 8 & 4 & 6 & 4 & - & - & 6 & 2 \\
\hline $\begin{array}{lllllll}\text { Revistas } & \ldots & \ldots & \ldots & \ldots & \ldots & \text {. }\end{array}$ & $\ldots$ & 6 & 3 & 4 & 3 & 5 & 2 & 10 & 3 \\
\hline $\begin{array}{llllll}\text { Periódicos } & \ldots & \ldots & \ldots & \ldots & \ldots\end{array}$ & $\ldots$ & 5 & 3 & 5 & 3 & 6 & 2 & 9 & 3 \\
\hline $\begin{array}{llllllll}\text { Cines } & \ldots & \ldots & \ldots & \ldots & \ldots & \ldots\end{array}$ & $\ldots$ & 3 & 2 & 2 & 1 & 5 & 2 & 6 & ? \\
\hline $\begin{array}{lllllll}\text { Confiterías } & \ldots & \ldots & \ldots & \ldots & \ldots\end{array}$ & $\ldots$ & 3 & 2 & 2 & 1 & 1 & - & 2 & -1 \\
\hline Total $\ldots \ldots \ldots c c c c c$. & $\cdots$ & 182 & 100 & 158 & 100 & 252 & 100 & 314 & 100 \\
\hline 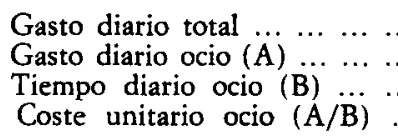 & $\begin{array}{l}\cdots \\
\cdots \\
\cdots \\
\cdots\end{array}$ & $\begin{array}{l}251 \\
182 \\
5,77 \\
31,54\end{array}$ & $\begin{array}{l}\text { ptas. } \\
\text { ptas. } \\
\text { horas } \\
\text { p/h. }\end{array}$ & $\begin{array}{l}185 \\
158 \\
5,67 \\
27,87\end{array}$ & $\begin{array}{l}\text { ptas. } \\
\text { ptas. } \\
\text { horas } \\
\text { p/h. }\end{array}$ & $\begin{array}{c}304 \\
252 \\
9,45 \\
26,67\end{array}$ & $\begin{array}{l}\text { ptas. } \\
\text { ptas. } \\
\text { horas } \\
\text { p/h. }\end{array}$ & $\begin{array}{r}468 \\
314 \\
6,12 \\
51,31\end{array}$ & $\begin{array}{l}\text { ptas. } \\
\text { ptas. } \\
\text { horas } \\
\text { p/h. }\end{array}$ \\
\hline
\end{tabular}

FuENTE: Encuesta Empleo del tiempo y recursos económicos de los jóvenes españoles, dirigida por José Luis Zárraga y realizada por ALEF por encargo de la Dirección General de la Juventud del Ministerio de Cultura en 1984. 


\section{CUADRO 6}

El ocio de la juventud española en 1894: mujeres según actividad

\begin{tabular}{|c|c|c|c|c|c|c|c|c|}
\hline & \multicolumn{2}{|c|}{$\begin{array}{c}\text { Mujer } 15.24 \\
\text { estudiantes }\end{array}$} & \multicolumn{2}{|c|}{$\begin{array}{c}\text { Mujer } 15-24 \\
\text { paradas }\end{array}$} & \multicolumn{2}{|c|}{$\begin{array}{c}\text { Mujer } 15-24 \\
\text { ocupadas }\end{array}$} & \multicolumn{2}{|c|}{$\begin{array}{c}\text { Mujer } 15-24 \\
\text { sus labores }\end{array}$} \\
\hline & Min. & $\%$ & Min. & $\%$ & Min. & $\%$ & Min. & $\%$ \\
\hline \multicolumn{9}{|l|}{ Tiempo diario } \\
\hline $\begin{array}{lllll}\text { Trabajo productivo } & \ldots & \ldots & \ldots \\
\text { Tiempo de estudio } & \ldots & \ldots & \ldots \\
\text { Trabajo doméstico } & \ldots & \ldots & \ldots \\
\text { Tiempo de ocio } & \ldots & \ldots & \ldots & \ldots \\
\text { Temo de tiempo } & \ldots & \ldots & \ldots & \ldots\end{array}$ & $\begin{array}{r}22 \\
386 \\
86 \\
281 \\
665\end{array}$ & $\begin{array}{r}2 \\
26 \\
6 \\
20 \\
46\end{array}$ & $\begin{array}{r}43 \\
62 \\
240 \\
414 \\
681\end{array}$ & $\begin{array}{r}3 \\
4 \\
17 \\
29 \\
47\end{array}$ & $\begin{array}{r}317 \\
62 \\
129 \\
292 \\
640\end{array}$ & $\begin{array}{r}22 \\
4 \\
9 \\
21 \\
44\end{array}$ & $\begin{array}{r}22 \\
20 \\
428 \\
338 \\
632\end{array}$ & $\begin{array}{r}2 \\
1 \\
30 \\
23 \\
44\end{array}$ \\
\hline Total $\ldots \ldots \ldots \ldots \ldots$ & 1.440 & 100 & 1.440 & 100 & 1.440 & 100 & 1.440 & 100 \\
\hline \multicolumn{9}{|l|}{ Ocio diario } \\
\hline 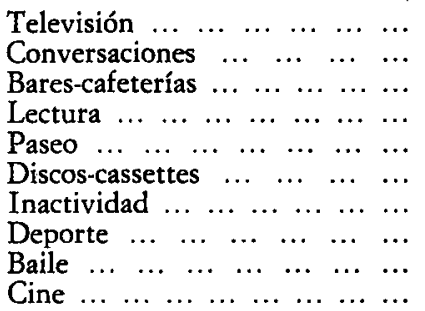 & $\begin{array}{r}110 \\
62 \\
31 \\
23 \\
19 \\
16 \\
8 \\
4 \\
4 \\
4\end{array}$ & $\begin{array}{r}39 \\
22 \\
11 \\
8 \\
7 \\
7 \\
3 \\
1 \\
1 \\
1\end{array}$ & $\begin{array}{r}162 \\
95 \\
41 \\
34 \\
24 \\
21 \\
19 \\
2 \\
13 \\
3\end{array}$ & $\begin{array}{r}38 \\
23 \\
10 \\
8 \\
6 \\
5 \\
5 \\
1 \\
2 \\
1\end{array}$ & $\begin{array}{r}116 \\
61 \\
37 \\
25 \\
22 \\
13 \\
9 \\
2 \\
4 \\
3\end{array}$ & $\begin{array}{r}39 \\
21 \\
13 \\
9 \\
7 \\
4 \\
3 \\
1 \\
2 \\
1\end{array}$ & $\begin{array}{r}170 \\
86 \\
16 \\
19 \\
14 \\
11 \\
17 \\
1 \\
3 \\
1\end{array}$ & $\begin{array}{r}50 \\
25 \\
5 \\
6 \\
4 \\
3 \\
5 \\
1 / 2 \\
1 \\
1 / 2\end{array}$ \\
\hline Total $\ldots \ldots \ldots \ldots \ldots$ & 281 & 100 & 414 & 100 & 292 & 100 & 338 & 100 \\
\hline & Ptas. & $\%$ & Ptas. & $\%$ & Ptas. & $\%$ & Ptas. & $\%$ \\
\hline \multicolumn{9}{|l|}{ Gasto diario en ocio } \\
\hline 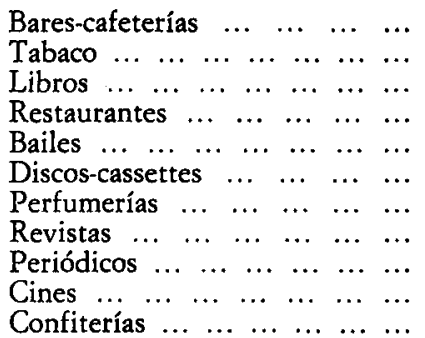 & $\begin{array}{r}45 \\
17 \\
23 \\
11 \\
7 \\
3 \\
4 \\
3 \\
3 \\
1 \\
4\end{array}$ & $\begin{array}{r}38 \\
14 \\
20 \\
9 \\
6 \\
2 \\
3 \\
2 \\
2 \\
1 \\
3\end{array}$ & $\begin{array}{r}39 \\
20 \\
11 \\
8 \\
9 \\
-\quad 12 \\
7 \\
2 \\
5 \\
3\end{array}$ & $\begin{array}{r}34 \\
17 \\
9 \\
7 \\
8 \\
-10 \\
6 \\
2 \\
4 \\
3\end{array}$ & $\begin{array}{r}52 \\
24 \\
16 \\
19 \\
8 \\
7 \\
18 \\
9 \\
4 \\
2 \\
3\end{array}$ & $\begin{array}{r}32 \\
15 \\
10 \\
12 \\
5 \\
4 \\
11 \\
6 \\
2 \\
1 \\
2\end{array}$ & $\begin{array}{r}29 \\
17 \\
11 \\
4 \\
7 \\
5 \\
20 \\
8 \\
3\end{array}$ & $\begin{array}{r}25 \\
15 \\
10 \\
4 \\
6 \\
5 \\
18 \\
7 \\
3 \\
2 \\
5\end{array}$ \\
\hline TOTAL $\ldots \ldots \ldots \ldots$ & 121 & 100 & 116 & 100 & 162 & 100 & 111 & 100 \\
\hline 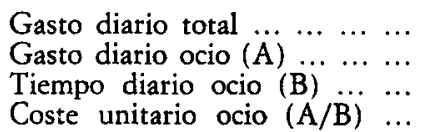 & $\begin{array}{r}155 \\
121 \\
4,68 \\
25,85\end{array}$ & $\begin{array}{l}\text { ptas. } \\
\text { ptas. } \\
\text { horas } \\
\text { p/h. }\end{array}$ & $\begin{array}{r}155 \\
116 \\
6,90 \\
16,81\end{array}$ & $\begin{array}{l}\text { ptas. } \\
\text { ptas. } \\
\text { horas } \\
\text { p/h. }\end{array}$ & $\begin{array}{r}257 \\
162 \\
4,87 \\
33,26\end{array}$ & $\begin{array}{l}\text { ptas. } \\
\text { ptas. } \\
\text { horas } \\
\text { p/h. }\end{array}$ & $\begin{array}{r}204 \\
111 \\
5,63 \\
19,72\end{array}$ & $\begin{array}{l}\text { ptas. } \\
\text { ptas. } \\
\text { horas } \\
\text { p/h. }\end{array}$ \\
\hline
\end{tabular}

FuENTE: Encuesta Empleo del tiempo y recursos económicos de los jóvenes españoles, dirigida por José Luis Zárraga y realizada en 1984 por ALEF por encargo de la Dirección General de la Juventud del Ministerio de Cultura. 
radas quienes disponen de más tiempo de ocio, y que son los ocupados y las ocupadas quienes disponen de mayores niveles de gasto en ocio. En realidad, la mayor parte de estos datos podrían parecer obvios, por lo que no precisan mayores comentarios. Pero hay algo que sí que llama poderosamente la atención, y es el dato relativo a los altos niveles de gasto en ocio de que disponen los parados masculinos (100 pesetas diarias más que los estudiantes, y sólo 60 pesetas menos que los ocupados). Este dato es precisamente el que confirma la teoría del soborno, que páginas atrás he apuntado como explicación de la sorprendente riqueza del ocio juvenil español. Los chicos parados presentan muy altos niveles de gasto en ocio. $Y$, dado que apenas pueden disponer de ingresos propios (puesto que el tiempo de trabajo, chapucero, trapicheante o subterráneo, de que disponen cada día es de tan sólo un 6 por 100 , frente al 2 por 100 de los estudiantes y el 25 por 100 de los ocupados; véase cuadro 5), ello prueba que tales gastos diarios en ocio (nada menos que 252 pesetas diarias, cuando la media global para el conjunto de la juventud española es de sólo 182 pesetas al día; luego los parados gastan en ocio un 38 por 100 más que el joven español medio) son subvencionados a fondo perdido por las propias familias de las que dependen económicamente los parados.

En todo caso, tampoco conviene tomar este dato ingenuamente, llevándose las manos a la cabeza ante la enormidad del soborno. El dato es fiable, pero el sentido común nos dice que no parece lógico que los parados se peguen mejor vida que los estudiantes, por ejemplo, puesto que de ser así todos los estudiantes estarian deseando convertirse en parados: algo que la experiencia de la vida cotidiana desmiente por completo. ¿Qué pasa, pues? Sucede que esa cifra de gasto diario es un valor absoluto que hay que poner en relación con el total de tiempo de ocio. En efecto, los chicos parados gastan diariamente 100 pesetas más que los chicos estudiantes, pero es que, claro, los chicos parados tienen que enfrentarse a 225 minutos más de ocio diario que los chicos estudiantes. Es decir, los parados disponen de un 59 por 100 más de dinero que los estudiantes porque también les sobra un 67 por 100 más de tiempo libre que a los estudiantes. Luego el gasto en ocio no vale nada en sí mismo considerado, sino sólo en relación al montante de tiempo libre sobre el que debe ser invertido para transformarlo en ocio. En suma, los niveles de gasto en ocio deben compararse no por su valor absoluto, sino por su valor unitario: lo que cuenta es el gasto por unidad de tiempo. Tanto en el cuadro 4 como en los cuadros 5, 6, 9 y 10 aparece el dato final del coste unitario del ocio medido en pesetas gastadas por hora de ocio: éste, y no otro, debe ser el único dato que nos permita estimar el nivel de recursos materiales de que dispone cada categoría de jóvenes para invertir en su ocio (en el cuadro 11 volveremos sobre ello). Pues bien, en función de este dato, ya podemos reconciliar nuestras cifras con la vida cotidiana y con el sentido común; en efecto, no mucho, pero los chicos parados viven peor que los chi- 
cos estudiantes, puesto que cada hora de su ocio vale 1,20 pesetas menos (luego el soborno a los parados es menor, en términos relativos, que el premio a los estudiantes, después de todo).

Pero, naturalmente, son los ocupados quienes viven mejor de todos y quienes se costean un ocio más rico (variado, equilibrado y diversificado), dados sus altísimos niveles de gasto unitario en ocio, y ello tanto entre los chicos como entre las chicas. Ahora bien, eso, el llegar a estar ocupado, es precisamente lo que todos los chicos y las chicas querrían si pudieran, dada la riqueza de ocio que el estar ocupado proporciona (como sabe todo joven por la experiencia de sentido común de su vida cotidiana); pero es inútil que lo quieran, puesto que casi ninguno lo puede lograr: como he señalado en secciones anteriores, debido a la reciente evolución de las pirámides poblacional y ocupacional, las probabilidades de ocuparse que se le presentan hoy a cada joven son mínimas. La clave de todo el problema juvenil en general, y del ocio juvenil en particular, reside precisamente en las enormes dificultades y demoras con que para cada joven transcurre lo que podemos llamar su proceso de independización económica (también llamado de inserción o integración social), proceso que hoy se ve más retrasado, alargado, entorpecido, obstaculizado y dificultado que nunca ${ }^{11}$. Pues bien, es precisamente en función de la posición ocupada por relación a ese proceso de independización económica que la conducta de ocio se determina. Que es lo mismo que decir: la variable independiente que determina en última instancia la conducta relativa al ocio es el estado civil, como variable compleja que incluye tanto el grado de independencia económica como el grado de autonomía domiciliaria e independencia residencial.

Ahora bien, resulta extraordinariamente difícil cuantificar el grado de independización económica de los jóvenes y, por tanto, cuantificar su estado civil ${ }^{12}$. En los cuadros 7,8 y 8 bis aparecen reflejados determinados datos a todas luces insuficientes, dado que enmascaran bajo el mismo rótulo de «solteros activos» situaciones tan heterogéneas entre sí como puedan ser la soltera parada dependiente y la soltera ocupada independiente (cuya abismal

"Sobre el proceso de integración social de los jóvenes ha tenido lugar, en la Fundación Pablo Iglesias, un Seminario durante los meses de febrero y marzo de 1985 en el que sociólogos y economistas discutimos a puerta cerrada sobre nuestras escasas coincidencias y múltiples discrepancias acerca del desempleo juvenil. La dirección, diseño, coordinación y animación del Seminario corrieron a cargo de Luis Garrido Medina. El conjunto de ponencias y de informes sobre sesiones (uno de los cuales, el titulado «Dependencia y familia», corrió a cargo del autor de estas páginas) será próximamente recopilado y publicado en forma de libro por el Ministerio de Economía.

${ }_{12}$ Existe una publicación exhaustiva sobre las condiciones objetivas con que se enfrentan los jóvenes españoles actuales en su proceso de progresiva emancipación familiar. Se trata del primer volumen de la serie Intorme Juventud en España, del Ministerio de Cultura, titulado La inserción de los jóvenes en la sociedad, dirigido y redactado por José Luis Zárraga. Dado que acaba de salir al mercado, su consulta no ha sido todavía posible para la elaboración de estas páginas. Pero, indudablemente, es la fuente imprescindible para todo lo relativo a la variable «estado civil», entendida tal y como aquí se hace, de un modo que es deudor, al fin y al cabo, de José Luis Zárraga. 


\section{CUADRO 7}

El «estado civil» de la juventud española: su evolución desde 1973

\begin{tabular}{|c|c|c|c|c|c|c|}
\hline \multirow[b]{2}{*}{ Estado civil } & \multicolumn{3}{|c|}{ AÑ̃ 1973} & \multicolumn{3}{|c|}{ AÑo 1984} \\
\hline & $\begin{array}{l}\text { Ambos } \\
\text { sexos } \\
15-24\end{array}$ & $\begin{array}{c}\text { Varones } \\
15-24\end{array}$ & $\begin{array}{c}\text { Mujeres } \\
15-24\end{array}$ & $\begin{array}{l}\text { Ambos } \\
\text { sexos } \\
15-24\end{array}$ & $\begin{array}{c}\text { Varones } \\
15-24\end{array}$ & $\begin{array}{c}\text { Mujeres } \\
15-24\end{array}$ \\
\hline $\begin{array}{llll}\text { Solteros activos } & \ldots & \ldots \\
\text { Solteros inactivos } & \ldots & \ldots \\
\text { Casados activos } & \ldots & \ldots \\
\text { Casados inactivos } & \ldots & \ldots\end{array}$ & $\begin{array}{r}42 \\
46 \\
3 \\
9\end{array}$ & $\begin{array}{r}52 \\
42 \\
6 \\
-\end{array}$ & $\begin{array}{r}32 \\
50 \\
1 \\
17\end{array}$ & $\begin{array}{r}46 \\
44 \\
5 \\
5\end{array}$ & $\begin{array}{r}52 \\
43 \\
5 \\
-\end{array}$ & $\begin{array}{r}40 \\
44 \\
6 \\
10\end{array}$ \\
\hline TOTAL $\ldots \ldots \ldots \ldots$ & 100 & 100 & 100 & 100 & 100 & 100 \\
\hline
\end{tabular}

Fuentes: Para el año 1973, Visedo, Zárraga y Barrio, El empleo del tiempo de la población española, Gabinete de Investigación de Audiencia de RTVE, Madrid, 1976; para el año 1984, EPA del INE, 4. trimestre 1984, donde el primer grupo de edad es de 16 a 19 años. Elaboración propia.

\section{CUADRO 8}

El «estado civil» de la juventud española en 1984

\begin{tabular}{|c|c|c|c|c|c|c|c|c|c|}
\hline \multirow[b]{2}{*}{ Estado civil } & \multicolumn{3}{|c|}{ DE 15 A 19 AÑOS } & \multicolumn{3}{|c|}{ DE 20 A 24 AÑos } & \multicolumn{3}{|c|}{ DE 25 A 29 AÑOS } \\
\hline & $\begin{array}{l}\text { Ambos } \\
\text { sexos } \\
15-19\end{array}$ & $\begin{array}{l}\text { Varón } \\
15-19\end{array}$ & $\begin{array}{c}\text { Mujer } \\
15-19\end{array}$ & $\begin{array}{c}\text { Ambos } \\
\text { sexos } \\
20-24\end{array}$ & $\begin{array}{l}\text { Varón } \\
20-24\end{array}$ & $\begin{array}{c}\text { Mujer } \\
20-24\end{array}$ & $\begin{array}{l}\text { Ambos } \\
\text { sexos } \\
25-29\end{array}$ & $\begin{array}{l}\text { Varón } \\
25-29\end{array}$ & $\begin{array}{c}\text { Mujer } \\
25.29\end{array}$ \\
\hline $\begin{array}{l}\text { Solteros activos } \\
\text { Solteros inactivos. } \\
\text { Casados activos. } \\
\text { Casados inactivos. }\end{array}$ & $\begin{array}{r}40 \\
58 \\
1 \\
1\end{array}$ & $\begin{array}{r}46 \\
53 \\
1 \\
-\end{array}$ & $\begin{array}{r}33 \\
63 \\
1 \\
3\end{array}$ & $\begin{array}{r}52 \\
31 \\
9 \\
8\end{array}$ & $\begin{array}{r}58 \\
33 \\
9 \\
-\end{array}$ & $\begin{array}{l}46 \\
28 \\
10 \\
16\end{array}$ & $\begin{array}{r}36 \\
6 \\
37 \\
21\end{array}$ & $\begin{array}{r}45 \\
6 \\
48 \\
1\end{array}$ & $\begin{array}{r}26 \\
6 \\
26 \\
42\end{array}$ \\
\hline Total ...... & 100 & 100 & 100 & 100 & 100 & 100 & 100 & 100 & 100 \\
\hline
\end{tabular}

Fuente: EPA del INE, $4 .^{\circ}$ trimestre 1984. El primer grupo de edad es de 16 a 19 años. Elaboración propia. 


\section{CUADRO 8 bis}

El «estado civil» de la juventud española en 1984

\begin{tabular}{|c|c|c|c|}
\hline & $\begin{array}{l}\text { Ambos sexos } \\
15-29 \text { años }\end{array}$ & $\begin{array}{l}\text { Varones } \\
15.29 \text { años }\end{array}$ & $\begin{array}{l}\text { Mujeres } \\
15-29 \text { años }\end{array}$ \\
\hline \multicolumn{4}{|l|}{ Estado civil (A) } \\
\hline $\begin{array}{lllllllll}\text { Solteros activos } & \ldots & \ldots & \ldots & \ldots & \ldots & \ldots & \ldots & \ldots \\
\text { Solteros inactivos } & \ldots & \ldots & \ldots & \ldots & \ldots & \ldots & \ldots & \ldots \\
\text { Casados activos } & \ldots & \ldots & \ldots & \ldots & \ldots & \ldots & \ldots & \ldots \\
\text { Casados inactivos } & \ldots & \ldots & \ldots & \ldots & \ldots & \ldots & \ldots & \ldots\end{array}$ & $\begin{array}{l}43 \\
32 \\
15 \\
10\end{array}$ & $\begin{array}{l}50 \\
32 \\
18 \\
-\end{array}$ & $\begin{array}{l}36 \\
32 \\
12 \\
20\end{array}$ \\
\hline $\begin{array}{llllllllll}\text { Total } & \ldots & \ldots & \ldots & \ldots & \ldots & \ldots & \ldots & \ldots & \ldots\end{array}$ & 100 & 100 & 100 \\
\hline \multicolumn{4}{|l|}{ Estado civil (B) } \\
\hline 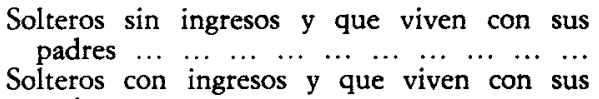 & 51 & 52 & 50 \\
\hline 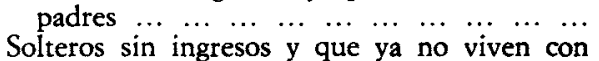 & 16 & 20 & 12 \\
\hline 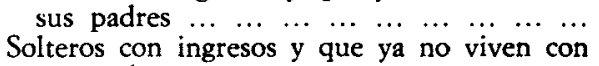 & 6 & 7 & 5 \\
\hline $\begin{array}{ccccccccc}\text { sus padres }{ }^{1} & \ldots & \ldots & \ldots & \ldots & \ldots & \ldots & \ldots & \ldots \\
\text { Casados } \sin \text { hijos } & \ldots & \ldots & \ldots & \ldots & \ldots & \ldots & \ldots & \ldots\end{array}$ & $\begin{array}{l}4 \\
7\end{array}$ & $\begin{array}{l}5 \\
6\end{array}$ & $\begin{array}{l}3 \\
8\end{array}$ \\
\hline 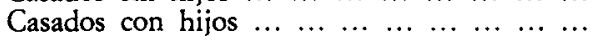 & 16 & 10 & 22 \\
\hline $\begin{array}{llllllllll}\text { TOTAL } & \ldots & \ldots & \ldots & \ldots & \ldots & \ldots & \ldots & \ldots & \ldots\end{array}$ & 100 & 100 & 100 \\
\hline
\end{tabular}

Fuentes: Para Estado civil (A), EPA del INE, $4 .^{\circ}$ trimestre 1984, donde el grupo de edad es de 16 a 29 años; para Estado civil (B), encuesta Omnibus/Juventud, realizada por ALEF, dirigida por José Luis Zárraga y encargada por la Dirección General de la Juventud del Ministerio de Cultura en 1984.

separación puede ser consultada en el cuadro 11). En todo caso, lo que sí puede advertirse muy bien en estos cuadros de estado civil es la extraordinaria transformación experimentada por las jóvenes españolas (cuadro 7) en cuanto respecta a su actividad (disminución de las inactivas y crecimiento de las activas, particularmente entre las casadas), de forma coherente con lo analizado por cuadros anteriores. En fin, tan sólo en el cuadro 8 bis, en la serie $\mathrm{B}$, aparecen estimaciones que se acercan más al objetivo que nos ocupa: identificar grados de independización económica. Es a base de estos datos que se puede construir la siguiente categorización de la soltería juvenil: solteros dependientes (que residen con sus padres y carecen de ingresos propios, sean inactivos, parados o estudiantes), solteros autónomos (que residen con sus padres, pero ya poseen alguna clase de ingresos propios) y, en fin, solteros independientes (que poseen ingresos propios y ya no residen con sus padres). Semejante simplificación permite jalonar las tres estaciones principales del proceso de independización económica o inserción social. 
Pues bien, los cuadros 9 y 10 analizan la conducta juvenil relativo al ocio en función, precisamente, de esta categorización del estado civil, desde la soltería dependiente (dependencia económica + responsabilidad familiar) hasta el matrimonio (independencia económica + responsabilidad familiar), pasando por la soltería autónoma (semidependencia económica + responsabilidad familiar) y la soltería independiente (independencia económica + irresponsabilidad familiar). Como resulta obvio, a juzgar por las cifras del cuadro 9 o del 10 , las diferencias conductuales del ocio dependiente al independiente resultan abismales: el ocio de los solteros independientes es el más rico de todos, mientras que el de los solteros dependientes es el más pobre (pero el de los casados y los solteros autónomos se halla muy próximo al de los solteros dependientes, ya que lo que cuenta es la presencia o ausencia de responsabilidades familiares).

Sólo tres cosas quiero destacar de los cuadros 9 y 10 . Ante todo, el que la variable «estado civil» es más discriminadora que la variable «sexo» (cuadro 4) o que la variable «actividad» (cuadros 5 y 6), dado que los diferenciales entre las puntuaciones de unos y otros estados civiles son mucho más altos que los diferenciales entre las puntuaciones de uno y otro sexo y más altos que los diferenciales entre las puntuaciones de unas y otras actividades. En segundo lugar, que las puntuaciones de las solteras independientes (cuadro 10) son más ricas y «masculinas» que la totalidad de las puntuaciones de las distintas clases de varones, a excepción de los chicos solteros independientes (lo que prueba que las chicas «liberadas» son las que mejor viven, precisamente por ser las menos «afeminadas», es decir, las menos económicamente dependientes); por lo tanto, no existen menús de ocio «masculino» (música y bares) y «femenino» (TV), sino menús «ricos» (o de independencia económica + irresponsabilidad familiar) frente a menús «pobres» (o de dependencia económica + responsabilidad familiar), como prueba el hecho de que sean las solteras liberadas quienes menos televisión miran y quienes más salen de casa a divertirse (muy por encima incluso de la gran mayoría de chicos jóvenes). $\mathrm{Y}$, en tercer lugar, que la discriminación sexual afecta muchísimo más a las casadas que a las solteras. En efecto, así como los chicos casados tienen un ocio bastante rico, casi tanto como el de los solteros independientes, pero, desde luego, mucho más que el de los solteros dependientes y autónomos, las chicas casadas, por el contrario, presentan un ocio muy pobre, alejadísimo de las solteras independientes y situado casi al mismo nivel de las solteras dependientes: más pobre, por lo tanto, incluso que el de las solteras autónomas. ¿Qué quiere esto decir? Que la discriminación sexual aparece vinculada al estado civil, puesto que es muy baja para las chicas solteras (dado que cada clase de soltería presenta muy pocas diferencias debidas al sexo: los chicos y chicas solteros dependientes se parecen mucho entre sí, los chicos y chicas autónomos se parecen mucho entre sí y los chicos y chicas solteros independientes se parecen mucho entre sí; luego lo que cuenta no 


\section{CUADRO 9}

El ocio de la juventud española en 1984: varones según estado civil

\begin{tabular}{|c|c|c|c|c|c|c|c|c|}
\hline & \multicolumn{2}{|c|}{$\begin{array}{c}\text { Varón } 15-24 \\
\text { solteros } \\
\text { dependientes }\end{array}$} & \multicolumn{2}{|c|}{$\begin{array}{c}\text { Varón } 15-24 \\
\text { solteros } \\
\text { autónomos }\end{array}$} & \multicolumn{2}{|c|}{$\begin{array}{c}\text { Varón } 15-24 \\
\text { solteros } \\
\text { independ. }\end{array}$} & \multicolumn{2}{|c|}{$\begin{array}{c}\text { Varón } 15-24 \\
\text { casados }\end{array}$} \\
\hline & Min. & $\%$ & Min. & $\%$ & Min. & $\%$ & Min. & $\%$ \\
\hline \multicolumn{9}{|l|}{ Tiempo diario } \\
\hline $\begin{array}{lllll}\text { Trabajo productivo } & \ldots & \ldots & \ldots \\
\text { Tiempo de estudio } & \ldots & \ldots & \ldots \\
\text { Trabajo doméstico } & \ldots & \ldots & \ldots \\
\text { Tiempo de ocio } & \ldots & \ldots & \ldots & \ldots \\
\text { Tiemto de tiempo } & \ldots & \ldots & \ldots & \ldots\end{array}$ & $\begin{array}{r}48 \\
300 \\
16 \\
376 \\
700\end{array}$ & $\begin{array}{r}3 \\
21 \\
1 \\
26 \\
49\end{array}$ & $\begin{array}{r}238 \\
115 \\
15 \\
390 \\
682\end{array}$ & $\begin{array}{r}17 \\
8 \\
1 \\
27 \\
47\end{array}$ & $\begin{array}{r}358 \\
53 \\
19 \\
407 \\
603\end{array}$ & $\begin{array}{r}25 \\
4 \\
1 \\
28 \\
42\end{array}$ & $\begin{array}{r}280 \\
68 \\
40 \\
360 \\
692\end{array}$ & $\begin{array}{r}19 \\
5 \\
3 \\
25 \\
48\end{array}$ \\
\hline 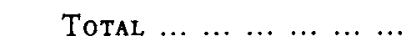 & 1.440 & 100 & 1.440 & 100 & 1.440 & 100 & 1.440 & 100 \\
\hline \multicolumn{9}{|l|}{ Ocio diario } \\
\hline 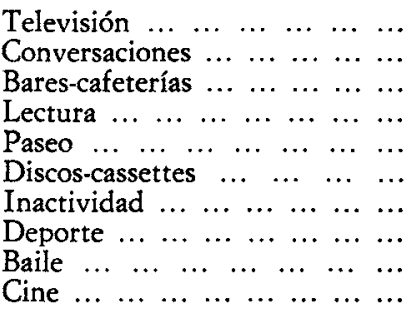 & $\begin{array}{r}126 \\
80 \\
51 \\
28 \\
23 \\
26 \\
21 \\
14 \\
3 \\
4\end{array}$ & $\begin{array}{r}34 \\
21 \\
14 \\
7 \\
6 \\
7 \\
5 \\
4 \\
1 \\
1\end{array}$ & $\begin{array}{r}100 \\
97 \\
78 \\
26 \\
22 \\
27 \\
13 \\
12 \\
10 \\
5\end{array}$ & $\begin{array}{r}25 \\
25 \\
20 \\
7 \\
6 \\
7 \\
3 \\
3 \\
3 \\
1\end{array}$ & $\begin{array}{r}95 \\
99 \\
101 \\
60 \\
11 \\
23 \\
9 \\
-\quad 5 \\
5\end{array}$ & $\begin{array}{r}23 \\
24 \\
25 \\
15 \\
3 \\
6 \\
2 \\
-1 \\
1\end{array}$ & $\begin{array}{r}108 \\
95 \\
53 \\
50 \\
17 \\
18 \\
12 \\
3 \\
4 \\
-\end{array}$ & $\begin{array}{r}30 \\
26 \\
15 \\
14 \\
5 \\
5 \\
3 \\
1 \\
1 \\
-\end{array}$ \\
\hline 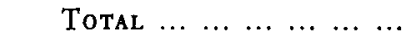 & 376 & 100 & 390 & 100 & 407 & 100 & 360 & 100 \\
\hline & Ptas. & $\%$ & Ptas. & $\%$ & Ptas. & $\%$ & Ptas. & $\%$ \\
\hline \multicolumn{9}{|l|}{ Gasto diario en ocio } \\
\hline 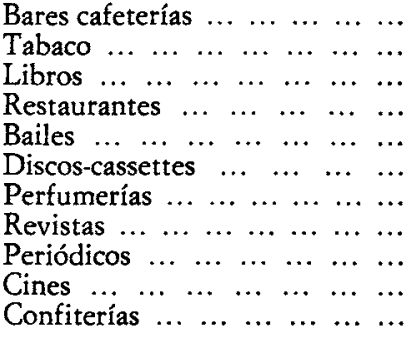 & $\begin{array}{r}71 \\
17 \\
20 \\
8 \\
4 \\
11 \\
-\quad \\
2 \\
4 \\
2 \\
2\end{array}$ & $\begin{array}{r}51 \\
12 \\
14 \\
6 \\
3 \\
8 \\
- \\
1 \\
3 \\
1 \\
1\end{array}$ & $\begin{array}{r}132 \\
33 \\
24 \\
27 \\
14 \\
18 \\
1 \\
8 \\
8 \\
4 \\
2\end{array}$ & $\begin{array}{r}49 \\
12 \\
9 \\
10 \\
5 \\
7 \\
- \\
3 \\
3 \\
1 \\
1\end{array}$ & $\begin{array}{r}150 \\
39 \\
16 \\
112 \\
10 \\
14 \\
32 \\
8 \\
11 \\
6 \\
2\end{array}$ & $\begin{array}{r}38 \\
10 \\
4 \\
28 \\
2 \\
4 \\
8 \\
2 \\
3 \\
1 \\
-\end{array}$ & $\begin{array}{r}115 \\
40 \\
58 \\
31 \\
2 \\
-\quad 18 \\
19 \\
13 \\
5 \\
2\end{array}$ & $\begin{array}{r}38 \\
13 \\
19 \\
10 \\
1 \\
- \\
6 \\
6 \\
4 \\
2 \\
1\end{array}$ \\
\hline 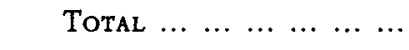 & 141 & 100 & 271 & 100 & 400 & 100 & 303 & 100 \\
\hline $\begin{array}{lllll}\text { Gasto diario total } & \ldots & \ldots & \ldots & \ldots \\
\text { Gasto diario ocio }(\mathrm{A}) & \ldots & \ldots & \ldots \\
\text { Tiempo diario ocio }(\mathrm{B}) & \ldots & \ldots \\
\text { Coste unitario ocio }(\mathrm{A} / \mathrm{B}) & \ldots\end{array}$ & $\begin{array}{c}141 \\
141 \\
6,27 \\
22,49\end{array}$ & $\begin{array}{l}\text { ptas. } \\
\text { ptas. } \\
\text { horas } \\
\text { p/h. }\end{array}$ & $\begin{array}{c}367 \\
271 \\
6,50 \\
41,69\end{array}$ & $\begin{array}{l}\text { ptas. } \\
\text { ptas. } \\
\text { horas } \\
\text { p/h. }\end{array}$ & $\begin{array}{r}646 \\
400 \\
6,78 \\
59,00\end{array}$ & $\begin{array}{l}\text { ptas. } \\
\text { ptas. } \\
\text { horas } \\
\text { p/h. }\end{array}$ & $\begin{array}{r}548 \\
303 \\
6,00 \\
50,50\end{array}$ & $\begin{array}{l}\text { ptas. } \\
\text { ptas. } \\
\text { horas } \\
\text { p/h. }\end{array}$ \\
\hline
\end{tabular}

FUENTE: Encuesta Empleo del tiempo y recursos económicos de los jóvenes españoles, dirigida por José Luis Zárraga, realizada en 1984 por ALEF y encargada por la Dirección General de la Juventud del Ministerio de Cultura. 


\section{CUADRO 10}

El ocio de la juventud española en 1984: mujeres según estado civil

\begin{tabular}{|c|c|c|c|c|c|c|c|c|}
\hline & \multicolumn{2}{|c|}{$\begin{array}{l}\text { Mujer } 15-24 \\
\text { solteras } \\
\text { dependientes }\end{array}$} & \multicolumn{2}{|c|}{$\begin{array}{l}\text { Mujer } 15-24 \\
\text { solteras } \\
\text { autónomas }\end{array}$} & \multicolumn{2}{|c|}{$\begin{array}{l}\text { Mujer } 15-24 \\
\text { solteras } \\
\text { independ. }\end{array}$} & \multicolumn{2}{|c|}{$\begin{array}{c}\text { Mujer } 15.24 \\
\text { casadas }\end{array}$} \\
\hline & Min. & $\%$ & Min. & $\%$ & Min. & $\%$ & Min. & $\%$ \\
\hline \multicolumn{9}{|l|}{ Tiempo diario } \\
\hline $\begin{array}{lllll}\text { Trabajo productivo } & \ldots & \ldots & \ldots \\
\text { Tiempo de estudio } & \ldots & \ldots & \ldots \\
\text { Trabajo doméstico } & \ldots & \ldots & \ldots \\
\text { Tiempo de ocio } & \ldots & \ldots & \ldots & \ldots \\
\text { Resto de tiempo } & \ldots & \ldots & \ldots & \ldots\end{array}$ & $\begin{array}{r}26 \\
286 \\
132 \\
320 \\
676\end{array}$ & $\begin{array}{r}2 \\
20 \\
9 \\
22 \\
47\end{array}$ & $\begin{array}{l}233 \\
129 \\
119 \\
302 \\
657\end{array}$ & $\begin{array}{r}16 \\
9 \\
8 \\
21 \\
46\end{array}$ & $\begin{array}{l}265 \\
107 \\
168 \\
278 \\
622\end{array}$ & $\begin{array}{r}18 \\
7 \\
12 \\
19 \\
44\end{array}$ & $\begin{array}{r}109 \\
36 \\
385 \\
302 \\
608\end{array}$ & $\begin{array}{r}8 \\
2 \\
27 \\
21 \\
42\end{array}$ \\
\hline $\begin{array}{lllllll}\text { Total } & \ldots & \ldots & \ldots & \ldots & \ldots & \ldots\end{array}$ & 1.440 & 100 & 1.440 & 100 & 1.440 & 100 & 1.440 & 100 \\
\hline \multicolumn{9}{|l|}{ Ocio diario } \\
\hline 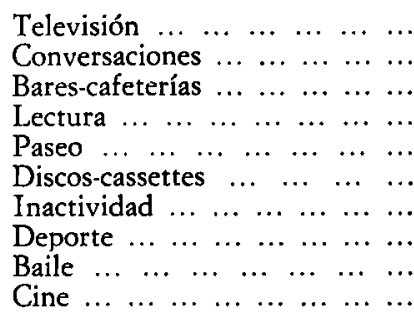 & $\begin{array}{r}132 \\
69 \\
31 \\
26 \\
18 \\
17 \\
13 \\
4 \\
5 \\
2\end{array}$ & $\begin{array}{r}42 \\
22 \\
9 \\
8 \\
6 \\
5 \\
4 \\
1 \\
2 \\
1\end{array}$ & $\begin{array}{r}121 \\
63 \\
32 \\
25 \\
26 \\
17 \\
8 \\
3 \\
6 \\
1\end{array}$ & $\begin{array}{r}40 \\
21 \\
11 \\
8 \\
8 \\
6 \\
3 \\
1 \\
2 \\
-\end{array}$ & $\begin{array}{r}69 \\
58 \\
59 \\
27 \\
18 \\
17 \\
7 \\
7 \\
3 \\
13\end{array}$ & $\begin{array}{r}25 \\
21 \\
21 \\
10 \\
6 \\
6 \\
3 \\
2 \\
1 \\
5\end{array}$ & $\begin{array}{r}146 \\
73 \\
13 \\
25 \\
22 \\
8 \\
10 \\
1 \\
3 \\
1\end{array}$ & $\begin{array}{r}49 \\
25 \\
4 \\
8 \\
7 \\
3 \\
3 \\
-1 \\
-\end{array}$ \\
\hline Total $\ldots \ldots \ldots \ldots$ & 320 & 100 & 302 & 100 & 278 & 100 & 302 & 100 \\
\hline & Ptas. & $\%$ & Ptas. & $\%$ & Ptas. & $\%$ & Ptas. & $\%$ \\
\hline \multicolumn{9}{|l|}{ Gasto diario en ocio } \\
\hline 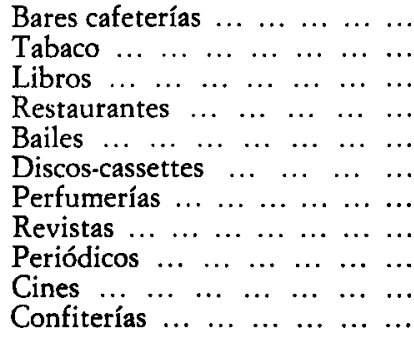 & $\begin{array}{r}41 \\
14 \\
22 \\
5 \\
5 \\
4 \\
5 \\
4 \\
2 \\
1 \\
4\end{array}$ & $\begin{array}{r}37 \\
13 \\
20 \\
5 \\
5 \\
4 \\
5 \\
4 \\
2 \\
1 \\
4\end{array}$ & $\begin{array}{r}48 \\
22 \\
8 \\
13 \\
3 \\
6 \\
10 \\
10 \\
2 \\
1 \\
4\end{array}$ & $\begin{array}{r}38 \\
17 \\
6 \\
10 \\
2 \\
5 \\
8 \\
8 \\
2 \\
1 \\
3\end{array}$ & $\begin{array}{r}93 \\
28 \\
46 \\
24 \\
31 \\
-\quad \\
18 \\
3 \\
6 \\
3 \\
3\end{array}$ & $\begin{array}{r}36 \\
11 \\
19 \\
9 \\
12 \\
-7 \\
1 \\
3 \\
1 \\
1\end{array}$ & $\begin{array}{r}27 \\
25 \\
17 \\
13 \\
-\quad 4 \\
8 \\
6 \\
5 \\
-4\end{array}$ & $\begin{array}{r}25 \\
23 \\
16 \\
12 \\
-4 \\
7 \\
5 \\
4 \\
-4\end{array}$ \\
\hline 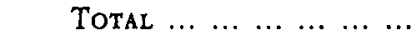 & 107 & 100 & 127 & 100 & 255 & 100 & 109 & 100 \\
\hline 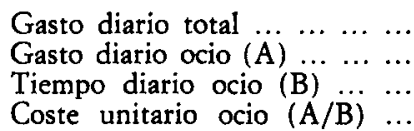 & $\begin{array}{r}111 \\
107 \\
5,33 \\
20,08\end{array}$ & $\begin{array}{l}\text { ptas. } \\
\text { ptas. } \\
\text { horas } \\
\text { p/h. }\end{array}$ & $\begin{array}{r}189 \\
127 \\
5,03 \\
25,25\end{array}$ & $\begin{array}{l}\text { ptas. } \\
\text { ptas. } \\
\text { horas } \\
\text { p/h. }\end{array}$ & $\begin{array}{r}457 \\
255 \\
4,63 \\
55,08\end{array}$ & $\begin{array}{l}\text { ptas. } \\
\text { ptas. } \\
\text { horas } \\
\text { p/h. }\end{array}$ & $\begin{array}{r}320 \\
109 \\
5,03 \\
21,67\end{array}$ & $\begin{array}{l}\text { ptas. } \\
\text { ptas. } \\
\text { horas } \\
\text { p/h. }\end{array}$ \\
\hline
\end{tabular}

Fuente: José Luis ZárRaGa, Empleo del tiempo y recursos económicos de los jóvenes españoles, Ministerio de Cultura, 1984. 
es tanto su sexo como el que su soltería sea dependiente, autónoma o independiente) y es muy alta para las chicas casadas, que son las clarísimas perdedoras de toda esta historia del emparejamiento amoroso ${ }^{13}$.

\section{Conclusión: el «ranking» de jóvenes}

A modo de resumen de todo cuanto he venido escribiendo, en el cuadro 11 se recogen, ordenados de mayor a menor, los indicadores de tiempo, gasto y

\section{CUADRO 11}

La estratificación de la juventud española en 1984

\begin{tabular}{|c|c|c|c|c|}
\hline Rango & Categorias & $\begin{array}{c}\text { Gastos ocio } \\
\text { (pesetas / día) } \\
\text { (A) }\end{array}$ & $\begin{array}{c}\text { Tiempo ocio } \\
\text { (horas /dia) } \\
\text { (B) }\end{array}$ & $\begin{array}{c}\text { Coste unidad } \\
\text { (pesetas/bora) } \\
\text { (A/B) }\end{array}$ \\
\hline $1 .^{\circ}$ & Varones solteros independientes & 400 & 6,78 & 59 \\
\hline $2 .^{\circ}$ & Mujeres solteras independientes & 255 & 4,63 & 55 \\
\hline 3. ${ }^{\circ}$ & $\begin{array}{llllll}\text { Varones ocupados } & \ldots & \ldots & \ldots & \ldots & \ldots\end{array}$ & 314 & 6,12 & 51 \\
\hline $4 .^{\circ}$ & $\begin{array}{llllllll}\text { Varones casados } & \ldots & \ldots & \ldots & \ldots & \ldots & \ldots\end{array}$ & 303 & 6,00 & 51 \\
\hline 5." & Varones solteros autónomos $\ldots \ldots$ & 271 & 6,50 & 42 \\
\hline 6." & Media global varones $15-24 \ldots \ldots \ldots$ & 230 & 6,37 & 36 \\
\hline $7 .^{\circ}$ & $\begin{array}{llllll}\text { Mujeres ocupadas } & \ldots & \ldots & \ldots & \ldots & \ldots\end{array}$ & 162 & 4,87 & 33 \\
\hline $8 .^{\circ}$ & Total ambos sexos $15-24 \ldots \ldots \ldots$ & 182 & 5,77 & 32 \\
\hline $9 .^{\circ}$ & $\begin{array}{llllll}\text { Varones estudiantes } & \ldots & \ldots & \ldots & \ldots & \ldots\end{array}$ & 158 & 5,67 & 28 \\
\hline $100^{\circ}$ & $\begin{array}{lllllll}\text { Varones parados } & \ldots & \ldots & \ldots & \ldots & \ldots & \ldots\end{array}$ & 252 & 9,45 & 27 \\
\hline $11 .^{\circ}$ & Mujeres estudiantes $\ldots \ldots \ldots c c c c c$ & 121 & 4,68 & 26 \\
\hline $12 .^{\circ}$ & Media global mujeres $15-24 \ldots \ldots \ldots$ & 131 & 5,17 & 25 \\
\hline $13 .^{\circ}$ & Mujeres solteras autónomas.$\ldots \ldots$ & 127 & 5,03 & 25 \\
\hline $14 .^{\circ}$ & Varones solteros dependientes $\ldots \ldots$ & 141 & 6,27 & 22 \\
\hline $150^{\circ}$ & $\begin{array}{lllllll}\text { Mujeres casadas } & \ldots & \ldots & \ldots & \ldots & \ldots & \ldots\end{array}$ & 109 & 5,03 & 22 \\
\hline $16 .^{\circ}$ & Mujeres solteras dependientes $\ldots \ldots$ & 107 & 5,33 & 20 \\
\hline $17 .^{\circ}$ & Mujeres dedicadas a sus labores $\ldots$ & 111 & 5,63 & 20 \\
\hline $18 .^{\circ}$ & $\begin{array}{lllllll}\text { Mujeres paradas } & \ldots & \ldots & \ldots & \ldots & \ldots & \ldots\end{array}$ & 116 & 6,90 & 17 \\
\hline
\end{tabular}

(A) Gastos diarios en actividades de ocio. Promedios en pesetas/día.

(B) Tiempo diario en actividades de ocio. Promedios en horas/día.

(A/B) Razón de gasto en ocio a tiempo de ocio. Cociente entre los gastos diarios en actividades de ocio (numerador) y el tiempo diario en actividades de ocio (denominador). Indicador relativo de calidad de ocio expresado en el coste unitario del tiempo de ocio: pesetas gastadas por bora de ocio.

Categorías: Dieciocho distintas desagregaciones del colectivo de jóvenes españoles de ambos sexos con edades comprendidas entre 15 y 24 años, obtenidas al cruzar las variables sexo, estado civil y actividad.

FuENTE: Encuesta Empleo del tiempo y recursos económicos de los jóvenes españoles, Ministerio de Cultura, 1984.

${ }^{13}$ La casi inexistencia de «discriminación» entre las solteras y la concentración de la totalidad de la discriminación de la mujer entre las casadas es, en última instancia, lo que también se desprende de un excelente artículo de Julio CarabaÑa, «¿Racionalidad o discriminación? Sobre los estudios acerca del sexismo ocupacional y la familia», en Rosa Conde (comp.), Familia y cambio social en España, Madrid, Centro de Investigaciones Sociológicas, 1982, pp. 229-258. 
coste unitario que aparecían al pie de los cuadros 4, 5, 6, 9 y 10 . Ello permite someter al mismo común denominador las distintas categorías heterogéneas de jóvenes en que resulta dividida la juventud española de 1984 en función de su desigualdad de recursos materiales. Creo que este cuadro es analíticamente importante (dado que sobre su importancia política prefiero no pronunciarme aquí). Creo que contribuye a llamar poderosamente la atención sobre un hecho grave: la ausencia de independencia económica que aqueja crónicamente a nuestra juventud, así como las desastrosas consecuencias culturales que de ello se derivan. Y creo, en fin, que la propia y llamativa evidencia de este cuadro me ahorra comentarios mayores.

Sólo subrayaré un hecho: los rangos superiores, aquellos ocupados por quienes gastan más de 50 pesetas por hora de ocio, aparecen cubiertos por los chicos y las chicas solteros independientes, por los chicos ocupados y por los chicos casados. En cambio, los rangos inferiores, aquellos ocupados por quienes no pueden llegar a gastar 25 pesetas por hora de ocio, aparecen cubiertos por los chicos y las chicas solteros dependientes, por las chicas casadas, por las chicas dedicadas a sus labores y por las chicas desempleadas. ¿Cabe mejor retrato-robot sobre la desoladora discriminación de los jóvenes, de la que somos responsables los adultos de la actual generación dirigente?

\section{Resumen del contenido del artículo}

La reciente evolución de la pirámide poblacional ha reducido el número de adultos y ha incrementado enormemente el número de jóvenes. Simultáneamente, pero de forma contradictoria con lo anterior, la reciente evolución de la pirámide ocupacional (estructura sexo/edad del mercado de trabajo) ha incrementado el número de empleos ocupados por los adultos y ha reducido muy fuertemente el número de empleos ocupados por los jóvenes. En el artículo se cuantifica este proceso y se exploran algunas de sus consecuencias, entre las que destaca la del crecimiento del tiempo de ocio de que disponen los jóvenes actuales, problema éste, el del ocio juvenil, del que se ofrece un estudio particularizado algo más profundo. 
NOTAS DE INVESTIGACION 